\begin{tabular}{|c|c|c|}
\hline EQE 983 & & ED: Senthil \\
\hline pp: 1-26 (col.fig.: Nil) & PROD. TYPE: COM & PAGN: Anuradha - SCAN: \\
\hline
\end{tabular}

EARTHQUAKE ENGINEERING AND STRUCTURAL DYNAMICS

Earthquake Engng Struct. Dyn. (2009)

Published online in Wiley InterScience (www.interscience.wiley.com). DOI: 10.1002/eqe.983

\title{
Self-centering structural systems with combination of hysteretic and viscous energy dissipations
}

\author{
Weng Yuen Kam*, ${ }^{*}$, Stefano Pampanin, Alessandro Palermo and Athol J. Carr \\ Department of Civil and Natural Resources Engineering, University of Canterbury, Private Bag 4800, \\ Christchurch 8020, New Zealand
}

SUMMARY

This paper presents an innovative set of high-seismic-resistant structural systems termed Advanced Flag-

9 Shaped (AFS) systems, where self-centering elements are combined in series and/or in parallel with alternative forms of energy dissipation (yielding, friction and viscous damping). AFS systems is developed

11 using the rationale of combining velocity-dependent with displacement-dependent energy dissipation for self-centering systems, particularly to counteract near-fault earthquakes. Non-linear time-history analyses

13 (NLTHA) on a set of four single-degree-of-freedom (SDOF) systems under a suite of 20 far-field and 20 near-fault ground motions are used to compare the seismic performance of AFS systems with the

15 conventional systems. It is shown that AFS system with a combination of hysteretic and viscous energy dissipations achieved greater performance in terms of the three performance indices. The use of friction

17 slip in series of viscous energy dissipation is shown to limit the peak response acceleration and induced base-shear. An extensive parametric analysis is carried out to investigate the influence of two design

19 parameters, $\lambda_{1}$ and $\lambda_{2}$ on the response of SDOF AFS systems with initial periods ranging from 0.2 to $3.0 \mathrm{~s}$ and with various strength levels when subjected to far-field and near-fault earthquakes. For the design

21 of self-centering systems with combined hysteretic and viscous energy dissipation (AFS) systems, $\lambda_{1}$ is recommended to be in the range of $0.8-1.6$ while $\lambda_{2}$ to be between 0.25 and 0.75 to ensure sufficient 23 self-centering and energy dissipation capacities, respectively. Copyright (C) 2009 John Wiley \& Sons, Ltd.

Received 3 January 2009; Revised 4 November 2009; Accepted 5 November 2009

KEY WORDS: self-centering systems; SDOF; near-fault responses; advanced flag-shape; performance25 based earthquake engineering (PBEE); energy dissipation

\footnotetext{
*Correspondence to: Weng Yuen Kam, Department of Civil and Natural Resources Engineering, University of Canterbury, Private Bag 4800, Christchurch 8020, New Zealand.

${ }^{\dagger}$ E-mail: wyk10@student.canterbury.ac.nz
}

Contract/grant sponsor: New Zealand Foundation for Research, Science and Technology (FRST); contract/grant number: UOAX0411

Copyright (C) 2009 John Wiley \& Sons, Ltd. 


\section{EQE 983}

W. Y. KAM ET AL.

\section{INTRODUCTION}

The unexpectedly high financial losses related to functional downtime and to structural and non-structural damage from recent large earthquakes near urban centers highlight the limitations behind the modern ductile designs. Stakeholders (owners, communities and regulatory authorities)'s structures. Some of the shortcomings within traditional seismic codes have been addressed in

7 the development of performance-based earthquake engineering (PBEE) [1]. The shift of societal expectation on the resilience of the engineered structures also implies a need for seismic resisting

9 systems that allow immediate occupancy in moderately strong events and shall not require significant repair and functional downtime; thus, guaranteeing the operation of essential emergency

11 services and minimal disruption to business continuity in extreme seismic events.

In search of alternative seismic-resisting systems that would satisfy the higher performance

13 objectives of the PBEE, structural systems have been developed with an emphasis on minimizing structural damage and downtime. Initially developed for pre-cast concrete structures under the

15 U.S. PRESSS research program in the 1990s [2-4] and later extended to bridge piers (bridge piers $[5,6]$, a series of innovative moment-resisting connections using post-tensioning concepts

17 were further developed for steel moment resisting frames (MRFs) [7-9] and more recently to timber (Laminated-Veneered-Lumber, LVL) multi-storey frame and wall buildings [10]. It was

19 demonstrated experimentally and numerically that these systems performed well under simulated seismic loading, exhibiting stable flag-shape hysteresis behaviour. Structural damage and residual

21 deformations (therefore repair cost) were minimized to negligible levels through the rocking mechanism and self-centering capabilities without any significant increase to peak responses, as

23 shown in pseudo-dynamic testing [4, 5, 10] and numerical analyses [6, 11-13]. Design guidelines for these self-centering systems have also been included in the and ACI design recommendations

25 [14], fib Bulletin no. 27 [15] and New Zealand design code [16]. Figure 1 presents some applications of these flag-shaped hysteresis systems.

27 Since the 1971 San Francisco earthquake, the peculiarities of the ground motions near the fault with the amplification of seismic wave in the direction of rupture (forward directivity) and/or

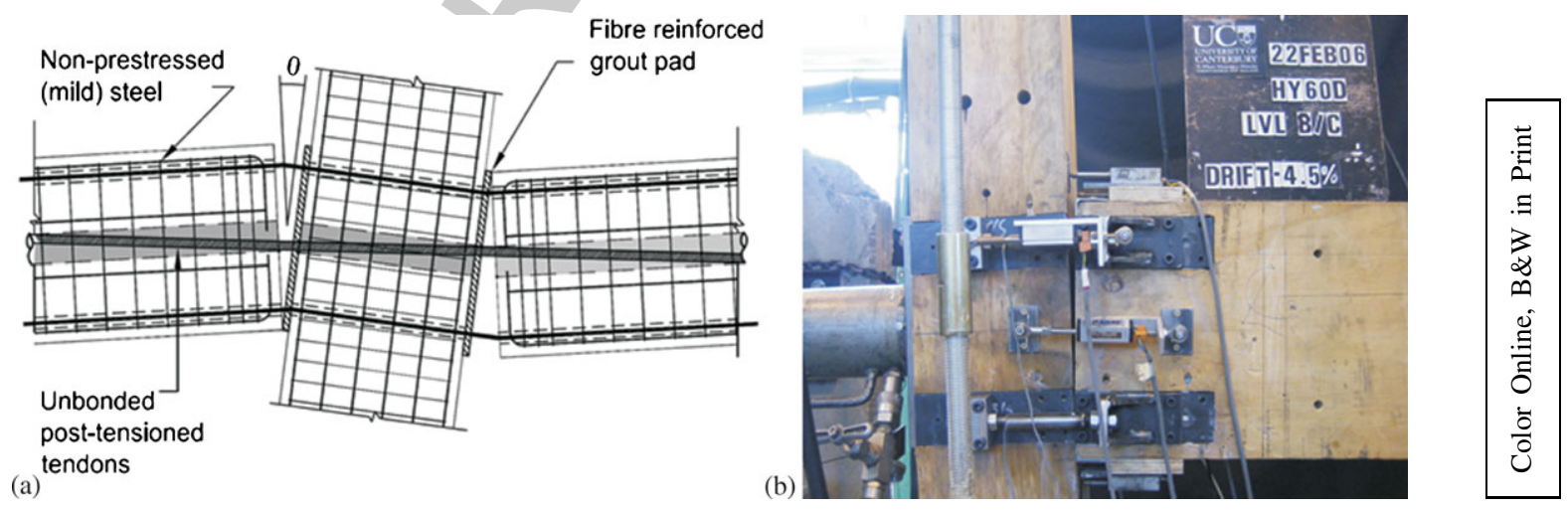

Figure 1. Un-bonded post-tensioned beam column joints: (a) Concrete with internal dissipative reinforcement [16] and (b) LVL beam-column joint with external mild-steel energy dissipators tested in New Zealand [10]. 


\section{EQE 983}

SELF-CENTERING STRUCTURAL SYSTEMS

1 permanent tectonic deformation (fling-step effect) have been observed [17-19]. These peculiar near-fault ground motions have been shown to cause significant displacement and ductility demand

3 in structures as well as a possible amplification in inter-storey shear demand for both long and short period conventional structures [20,21]. However, prior to the 1997 Uniform Building Code

5 [22], there was no near-fault amplification factor for the design hazard spectra. Furthermore, the current approach of amplification for near-fault effects has also been shown to be inconsistent with

7 recorded strong ground motion data [19].

Following the development of the self-centering systems and the uncertainties associated with

9 the near-fault earthquake directivity and fling effects, an advanced self-centering system, herein termed as Advanced Flag-Shape (AFS) [23], is proposed as an alternative solution for high-seismic

11 performance system in near-fault regions. In AFS systems, self-centering elements are combined in series and/or in parallel with alternative forms of energy dissipation (yielding, friction and

13 viscous damping). In this contribution, the concept of AFS systems and the combination of different energy dissipation types on the hysteresis shapes of the self-centering systems are first qualitatively

15 described. This comparative analysis is then extended to quasi-static cyclic (push-pull) analyses and NLTHA with two sets of 20 ground motion records. Two governing parameters on the seismic

17 response of various AFS SDOF systems are introduced and discussed. Finally, a parametric study of AFS systems is carried out, resulting in the development of a series of inelastic response spectra

19 that can be used for design and performance evaluation.

\section{SELF-CENTERING SYSTEMS PERFORMANCE MEASURES}

\section{2.1. Past research on self-centering systems SDOF behaviour}

A limited amount of previous studies on effect of hysteresis parameters on self-centering systems

23 have all concentrated on hysteretic-only (yielding or friction -damped) energy dissipations [11,24-26]. Several governing parameters were generally considered including strength (or strength reduction $R$ ) factor, post-yield stiffness and energy dissipation coefficient, $\beta$.

Studies $[11,12]$ have showed that the a flag-shaped hysteretic single-degree-of-freedom (SDOF)

27 system of equal or lesser strength can always match the response of a conventional elastoplastic or hysteretic SDOF system in terms of displacement ductility. Using a constant $R$-factor spectra

29 approach, Seo and Sause [26] investigated the ductility demand of hysteretic self-centering systems with different hysteresis shapes and different soil conditions. Increased post-yield stiffness and

31 energy dissipation coefficient $\beta$ were shown to decrease the ductility demand for self-centering systems. The use of displacement ductility demand as a response parameter of hysteretic self-

33 centering systems however can be a misleading damage parameter, as experimental data for these systems have shown that self-centering systems can be designed to have large displacement ductility 35 capacities without significant structural damages [2-5, 7, 8, 10].

Focusing on the equivalent damping ratio $\xi_{\text {eq }}$, several studies investigated the effect of different

37 hysteretic SDOF models such as self-centering flag-shape, elastoplastic and degrading stiffness hysteresis. However, these studies did not consider the influence of the different ground motions

39 (with directivity effects) or different design parameters of the models.

For this study, the approach is to adopt a constant strength SDOF model in order to establish

41 a comparable seismic response between the different systems. Ground motion with and without directivity effects are used to investigate its effect on self-centering systems. Previously higher 


\section{EQE 983}

W. Y. KAM ET AL.

1 displacement ductility demand and base-shear demand were observed for self-centering systems with hysteretic-only damping when subjected to near-field ground motions [27].

\section{2.2. PBEE performance measures}

To evaluate the performance objectives of performance-based structural systems, a set of defined

5 engineering demand parameters that are directly related to the structural and non-structural damage levels is required. The current PBEE framework [1] has acknowledged that maximum deforma-

7 tion (e.g. inter-storey drift) alone is inadequate to define the damage to a particular structure. Increasingly, it is recognized that residual deformation is an important and complementary damage

9 indicator [12,13]. In FEMA 450 [1], for example, quantifiable limits of residual drifts in relation to various structural performance levels are expressed. In addition, it is recognized that some non-

11 structural elements can be acceleration-sensitive [1], in which excessive acceleration can lead to damage and loss of functionality of the structure. Therefore, three non-dimensionless performance

13 indices (maximum drift $\psi_{\mathrm{M}}$, residual drift $\psi_{\mathrm{R}}$ and maximum acceleration $\psi_{\mathrm{A}}$ of the SDOF systems) are used.

\section{2.3. Global PBEE performance matrix}

Extending the concept of multi-level performance levels from FEMA 450 [1] and the 3D perfor-

17 mance matrix based on a combination of maximum and residual deformations suggested by Pampanin et al. [12], it is suggested that a global PBEE performance matrix should include the

19 three performance measures that take into account the structural and non-structural damage. The global PBEE performance matrix, shown schematically in Figure 2, represents a graphical view of

21 the concept of accounting for the three performance measures, for a given level of seismic intensity associated with a specified return period. This represents an improved version of FEMA approach

23 (e.g. FEMA 450 [1]) of quantifying global performance level as a combination of structural and non-structural performance levels, associated with physical damage indicators such as drift

25 limits.

\subsection{Normalized strength ratio}

27 Lastly, to make reasonable comparison between each system, the design strength ratio has to be considered, which represents the maximum force demand on the structural system itself. A normal-

29 ized strength ratio, $\psi_{\mathrm{S}}$, taken as the ratio of the base-shear to the weight of the SDOF system, $W_{\text {SDOF, }}$ is herein used as a performance measure.

$$
\psi_{\mathrm{S}}=\frac{V_{\mathrm{Base}}}{W_{\mathrm{SDOF}}}=C_{\mathrm{s}}=\frac{S_{\mathrm{a}}}{R / I}
$$

where $S_{\mathrm{a}}$ is the design spectral response acceleration, $I$ is the importance factor and $R$ is the

33 strength reduction factor. As this study adopts a constant-strength spectra approach, non-linear SDOF with constant strength, $V_{\text {Base }}$ with varying stiffness and periods are used to generate the 35 inelastic spectra in Section 6. 


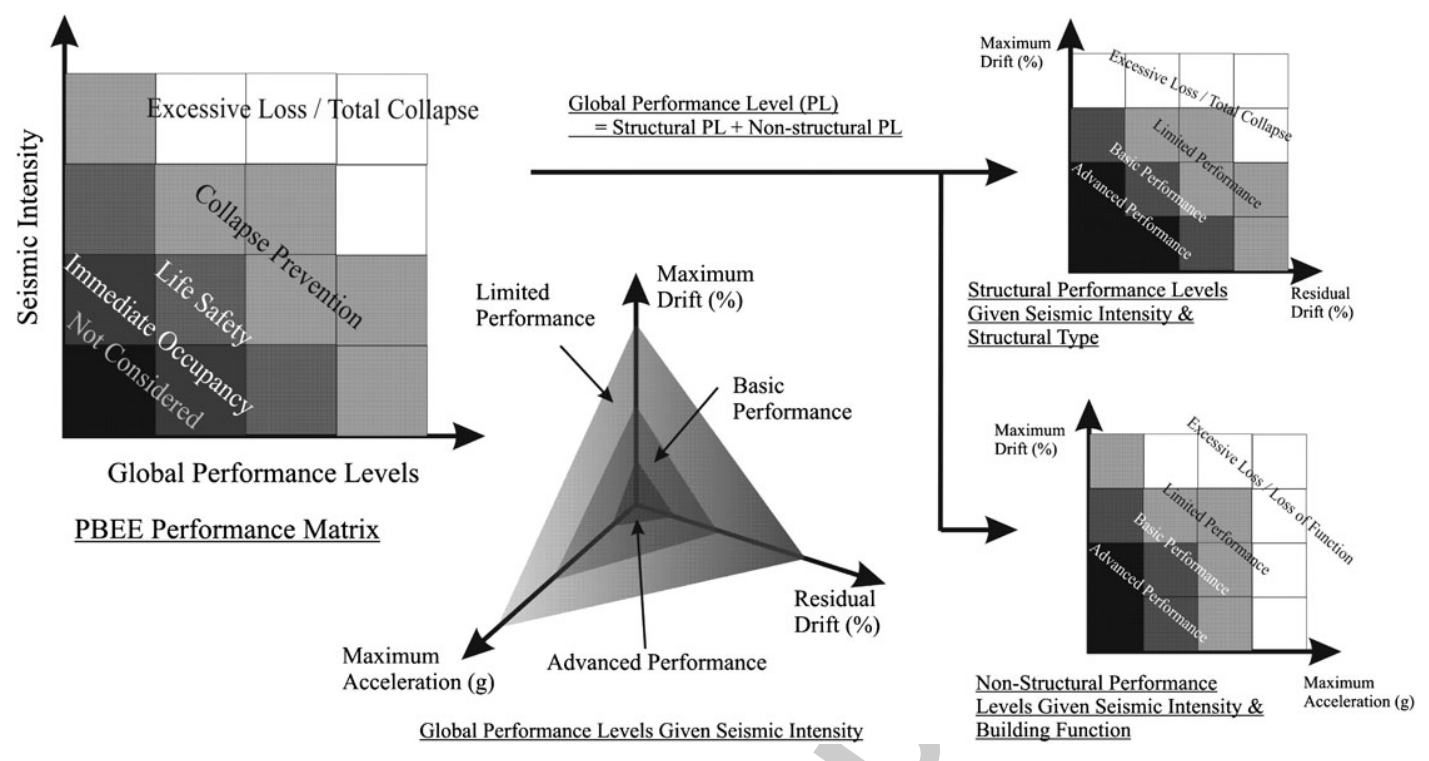

Figure 2. The concept of global PBEE performance matrix with performance levels as function of maximum drifts, residual drifts and floor accelerations.

\section{CONCEPTUAL DEVELOPMENT OF ADVANCED FLAG-SHAPE SYSTEMS}

\subsection{Traditional hysteretic self-centering systems}

3 As discussed, numerous research, both experimental and numerical in the past two decades have culminated in substantial knowledge base [2-11] and codification of the design of the hysteretic self-centering systems [14-16]. More recent developments within the traditional hysteretic selfcentering systems include the extension to other materials including steel $[7-9,28,29]$ and timber

7 [10]. In addition, the concept has also been extended to different forms in which the self-centering capacity is derived not from un-bonded post-tensioning tendons, but from self-centering braces

9 [30-32] and Shape Memory Alloy (SMA) elements [33] also in base isolation application [34].

Regardless the source of self-centering elements (from un-bonded pre-stressing tendons, self-

11 centering braces or SMA), traditional self-centering system still relies on the energy dissipating capability from additional energy dissipation hysteretic/yielding devices (either inherent (as in

13 SMA), internal or external). The self-centering behaviour can be modelled numerically with an idealized bi-linear elastic spring [35], as shown in Figure 3(a). In order to supply sufficient energy

15 dissipation capacity to the self-centering system, additional mild-steel elements (reinforcement bars or yielding angles) were used as hysteretic damping [2-11,36]. More recent research have

17 used friction hysteretic dampers as energy dissipation elements [37, 38]. While friction hysteretic damping has ideally a much higher initial stiffness, the additional hysteretic energy dissipation

19 can still be adequately modelled as a bi-linear elasto-plastic (with zero post-yielding stiffness in this case) spring element (Figure 3(b)). The traditional hysteretic self-centering system can be

21 modelled as the bi-linear elasto-plastic spring combined in parallel with the bi-linear elastic spring, 


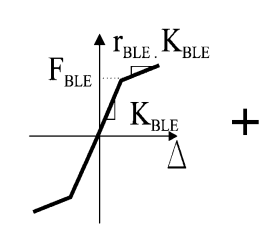

Un-bonded posttensioning tendons

(a)

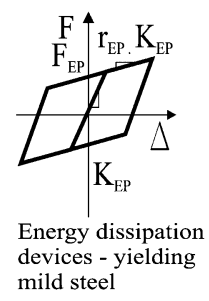

(b)

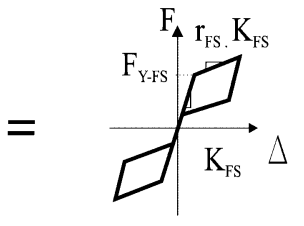

Self-centering Flag-shape Hysteresis

(c)

Figure 3. (a) Bi-linear elastic spring model (re-centering); (b) bi-linear elastoplastic spring model (hysteretic energy dissipation); and (c) idealized hysteretic rule for self-centering FS system [16].

1 as shown in its idealized form in Figure 3(c). For brevity, traditional self-centering flag-shape hysteresis system (with hysteretic energy dissipation) is herein referred to as FS system.

\section{3.2. Limitations of hysteretic (displacement-proportional) damping under near-fault excitations}

While the traditional hysteretic dissipative (i.e. displacement-proportional dissipation) systems may

5 be effective in typical far-field earthquakes, such systems may develop lower-than-expected energy dissipation in low-cycle ground motions, characteristics of the near-fault excitation. This is evident

7 in numerical studies $[20,21]$ that have shown that modern ductile multi-storey frame structures can undergo severe inelastic deformations in near-fault excitations, generating excessively high

9 ductility demand on the structural elements, particularly tall and flexible structures (of moderate to long periods).

11 The conventional assumption of (area-based) equivalent viscous damping, $\xi_{\text {SDOF }}$, and the associated force reduction factor, $R$, are based on the assumption of a full-cycle hysteresis response

13 of the SDOF systems to achieve the implied hysteretic energy dissipation [39]. In addition, these are further calibrated with dynamic analysis using ground motion records without any directivity

15 effects [39]. For hysteretic self-centering FS systems with moderately low damping, with typical values of $\xi_{\mathrm{FS}}$ in between 10 and $15 \%$ [40], the peculiar effects of near-fault excitations may lead to

17 lower than expected energy dissipation and thus less satisfactory performance of the FS systems.

\subsection{BLEV systems-velocity-proportional dissipating mechanisms combination in parallel}

19 with self-centering contribution

In order to achieve adequate energy dissipation capacity under near-fault excitations, supplementary

21 velocity-proportional passive dampers can be added to self-centering systems. Several researches have combined alternative energy dissipation (friction or viscous) in parallel with self-centering

23 elements, particularly for structural walls [37, 41-43], steel moment frames [29, 38, 44] and bridges [6, 43]. Christopoulos et al. [31] have proposed various energy dissipation types (yielding, friction 25 and viscous) in parallel with self-centering elements within a self-centering brace units. Such single-type dissipation in parallel with self-centering element can be modelled using a velocity-

27 proportional dashpot in parallel with bi-linear elastic self-centering spring, as shown in Figure 4. Such a combination of bi-linear elastic spring in parallel with viscous dashpot is herein called 29 BLEV systems. 


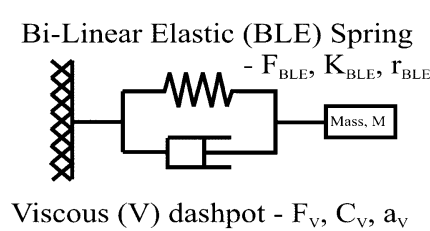

(a)

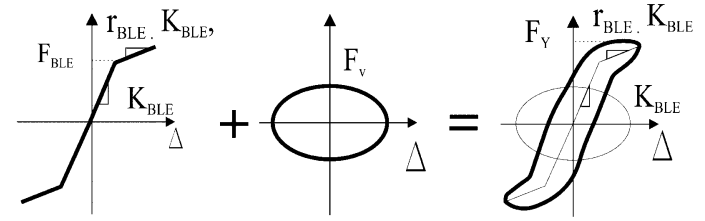

(b)

Figure 4. BLEV system: (a) schematic SDOF model and (b) idealized hysteretic model.

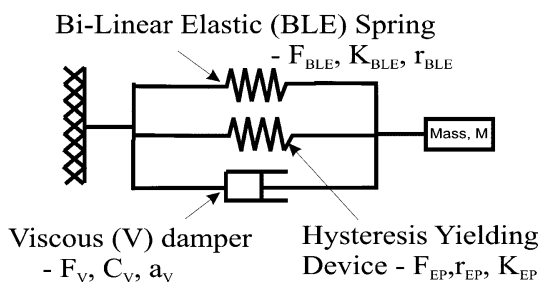

(a)

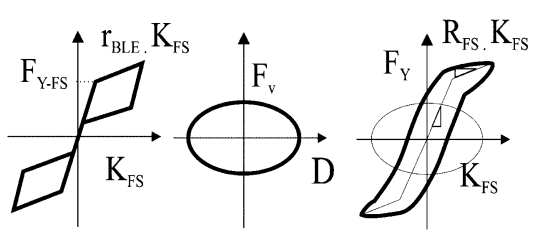

(b)

Figure 5. AFS1 system: (a) schematic SDOF model system and (b) idealized hysteretic model.

1 Intuitively, added velocity-proportional dampers yield higher energy dissipation capacity under near-fault excitations. However, self-centering systems with viscous-only damping would encounter limited energy dissipation and excessive induced damper force in scenario of relatively low or excessively high excitation velocity, respectively. Parallel lessons can be learnt from the use of

5 supplementary viscous dampers in parallel with base-isolation system, where, as noted by Kelly [32], where added viscous damping reduces base-shear but increases floor acceleration and inter-

7 storey drifts.

\subsection{AFS systems-velocity-proportional and displacement-proportional dissipating mechanisms}

9 combined in parallel with self-centering contribution

Given the limitations of either hysteretic-only or viscous-only energy dissipations, the possibility

11 of combining different dissipation mechanisms in parallel and/or in series within the self-centering systems becomes more attractive. Herein, two other AFS systems are briefly discussed: AFS1 and

13 AFS2. One variant of AFS systems is to combine in parallel displacement-proportional damping and velocity-proportional damping with self-centering elements (herein referred to AFS1). Figure 5

15 shows the idealized SDOF model for the hysteresis behavior of the AFS1 system. Displacementproportional damping can provide sufficient energy dissipation and strength at low excitation

17 velocity while the inherent advantages of velocity-proportional damping can reduce the displacement demand at high excitation velocity.

19 The combination of various dissipative mechanisms is not entirely novel and the concept has been widely used for base-isolation systems, where supplementary dampers are used in parallel

21 or in series with lead-rubber-bearing (LRB) isolators [45, 46]. It has been shown that the use of frictional dampers (e.g. LRB) in parallel with viscous dampers can reduce maximum responses in near-fault events without significant increase in base-shear [45]. 


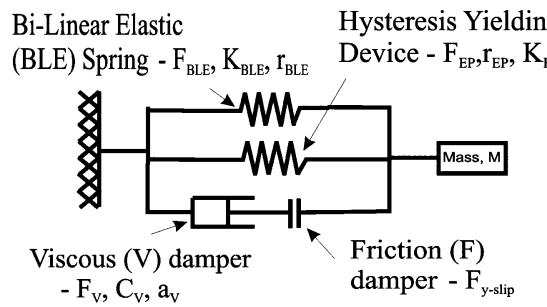

(a)

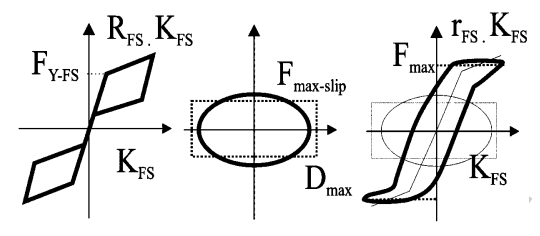

(b)

Figure 6. AFS2 system: (a) schematic SDOF model and (b) idealized hysteretic model.

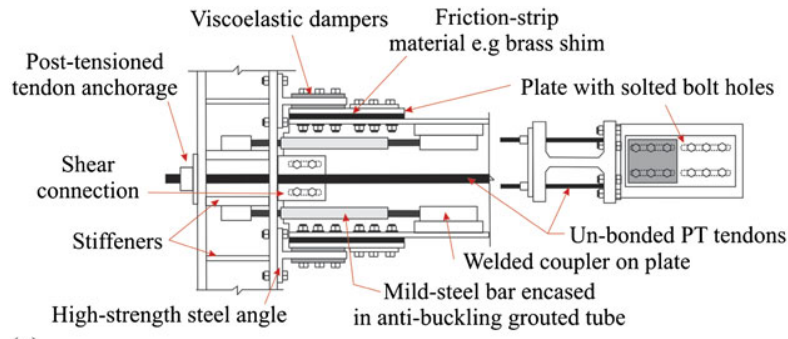

(a)

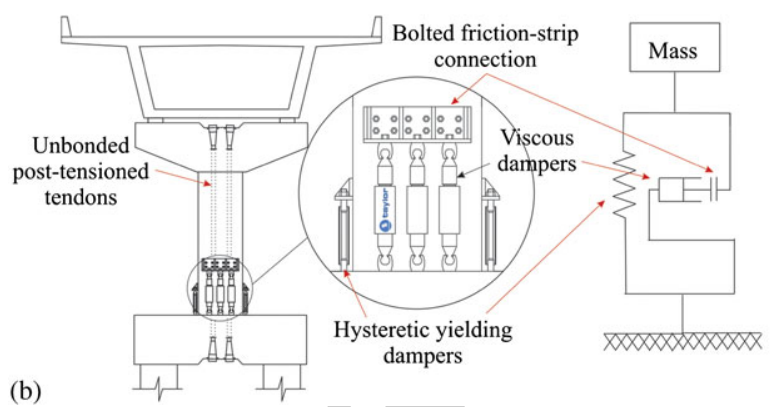

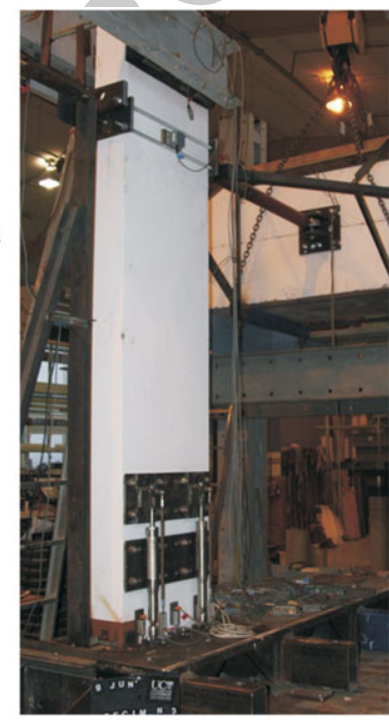

(c)

Figure 7. (a) AFS2 connections for moment-resisting steel frame; (b) AFS2 precast concrete bridge pier (adopted from [43]); and (c) BLEV connection structural wall [43].

1 The second variant of AFS system, herein referred to as Advanced Flag-Shape 2 (AFS2) system, utilizes a combination of a velocity-dependent damper in series with a friction-slip element, in place of the linear viscous damper alone in the AFS1 systems. The schematic SDOF of the AFS2 system is given in Figure 6(a). Figure 6(b) provides an idealized hysteretic behaviour of the

5 AFS2 system, with the distinct characteristic being the pre-defined maximum force generated from velocity-dependent dampers. Alternative, AFS2 configuration can be achieved by using highly

7 non-linear viscous dampers within the AFS1 system.

\subsection{Practical implementation of AFS systems}

9 The AFS systems described here are generally implementable with the existing technology and devices. Previous work by Kurama [41] have presented some practical implementations of the 
1 BLEV system for precast concrete walls and frames. Marriott [43] has performed shaking-table test on BLEV and AFS1 systems on structural walls as shown in Figure 7(c). In their contributions

3 [31, 32], Christopoulos, Tremblay and co-authors have implemented, tested and patented a practical self-centering brace device with parallel alternative energy dissipation devices, similar to the

5 AFS systems as shown in Figure 6(a). Herein, some additional conceptual applications of the AFS2 connections for precast concrete bridge-pier and steel moment-resisting frames are shown

7 in Figures 7(a) and (b).

\section{AFS SDOF MODELS GOVERNING PARAMETERS}

\section{4.1. SDOF hysteretic models}

Four SDOF hysteretic models are considered: (a) bi-linear ElastoPlastic model (EP), (b) flag-shape

11 hysteresis model (FS), (c) Bi-Linear Elastic in parallel with Viscous damper model (BLEV), (d) Advanced Flag-Shaped 2 model (AFS2). The schematic SDOF model and idealized hysteretic

13 model for FS, BLEV and AFS2 are as shown in Figures 2, 4 and 6.

The SDOF systems are taken to be representing of a prototype bridge pier (Figure 8(a) and (b)), designed to drift of $2 \%$ with respect to a monolithic reinforced concrete system. The backbone force-displacement capacity curve is given in Figure 8(c). The prototype SDOF structure has an

17 effective period of $1.6 \mathrm{~s}$ and an initial period of $1.0 \mathrm{~s}$. In order to make comparisons between each connection system, the critical section at the base-to-foundation interface was assigned

19 similar monotonic force-displacement loading envelope. Owing to the complex nature of the velocity-proportional dampers' contribution, two critical points were made constant for each SDOF

21 systems - (a) the 'yield' point and (b) the ultimate point.

\subsection{Equivalent viscous damping, $\xi_{\mathrm{eq}}$, and excitation velocity}

23 The SDOF models are calibrated to achieve a target monotonic force-displacement envelope under cyclic push-pull analysis with assumed sinusoidal excitation velocity of $150 \mathrm{~mm} / \mathrm{s}(0.47 \mathrm{~Hz}$ at $160 \mathrm{~mm}$ amplitude corresponding to $2 \%$ drift of the prototype SDOF). The choice of the excitation velocity is based on the minimum peak ground velocity (PGV) of earthquakes of large magnitude $\left(M_{\mathrm{w}} \geqslant 6\right.$ and peak ground acceleration, PGA, $\left.\geqslant 0.4 g\right)$. The calibrated SDOF models

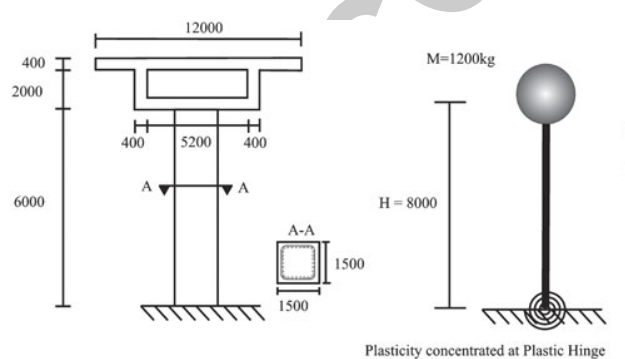

(a) (b)

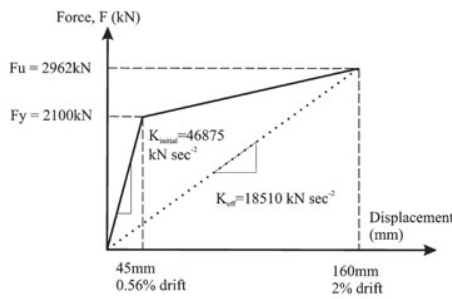

(c)

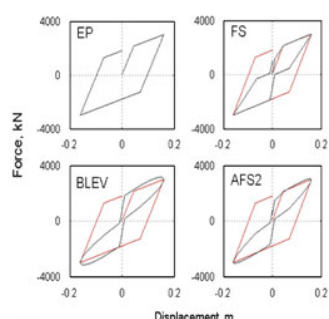

(d)

Figure 8. (a) Prototype Bridge Pier; (b) simple SDOF representation; (c) design force-displacement response of the SDOF model; and (d) hysteresis of the calibrated SDOF models. 
Table I. Equivalent viscous damping, $\xi$, of the calibrated SDOF models.

\begin{tabular}{lccc}
\hline & \multicolumn{3}{c}{ Area-based equivalent viscous damping, $\xi(\%)$} \\
\cline { 2 - 4 } SDOF model & $V=150 \mathrm{~mm} / \mathrm{s}$ & $V=300 \mathrm{~mm} / \mathrm{s}$ & $V=450 \mathrm{~mm} / \mathrm{s}$ \\
\hline EP & & 31.2 & \\
FS & 18.1 & 18.6 & 34.9 \\
BLEV & 17.0 & 28.1 & 29.7 \\
AFS2 & 24.1 & \\
\hline
\end{tabular}

1 and the associated $\xi_{\text {eq }}$ are shown in Figure 8(d) and Table I. As expected, systems with velocityproportional damping would generate higher amount of energy dissipation (as measured by $\xi_{\text {eq }}$ ).

3 However as discussed in Section 3.2, for near-fault excitation, the non-linear peak responses are no longer a function of the implied energy dissipated under the $\xi_{\text {eq }}$ assumption. The corrollary of

5 this will be evident when the hysteretic-dissipation-only (EP and FS) systems are compared, using NTHA, to systems with velocity-proportional viscous damping.

\section{4.3. Governing design parameters for AFS systems}

A well-designed AFS system would have adequate self-centering capacity and energy dissipation

9 under any excitation (low or high excitation velocity). In order to achieve this, two parameters are suggested: $\lambda_{1}$ and $\lambda_{2}$.

11 The first parameter is the moment contribution ratio $\lambda_{1}$ and it is typically adopted in the design of traditional flag-shape systems [14-16]. $\lambda_{1}$ in its generic form represents the force or moment

13 ratio between the self-centering contribution and the energy dissipation contribution, as shown in Equation (2), with reference to the symbols used in Figures 4-6

$$
\lambda_{1}=\frac{M_{\text {recentering }}}{M_{\text {dissipating }}} \approx \frac{F_{\mathrm{BLE}}}{F_{\mathrm{EP}}+F_{\mathrm{V}}}
$$

The inverse of $\lambda_{1}$ is also typically used as a governing parameter of self-centering system as

17 the energy dissipation coefficient, $\beta$ :

$$
\beta=1 / \lambda_{1}=M_{\text {dissipating }} / M_{\text {recentering }} \leqslant 0.5[14]
$$

19 For traditional hysteretic FS systems, a fully self-centering capacity can, in principle, be guaranteed by assuming an appropriate force/moment contribution ratio, $\lambda_{1} \geqslant 1$ or $\lambda_{1} \geqslant 1.15$ [16] when

21 the possible material over-strength in energy dissipating devices is considered. To reaffirm the same threshold value for $\lambda_{1}$ for AFS systems, push-pull analyses are carried out with varying

$23 \lambda_{1}$ values and results are presented in Figure 9. For the FS system, it was observed that full static self-centering can be achieved with $\lambda_{1}>1$. 2 . For BLEV systems (viscous-only dissipation) the 25 dynamic residual displacement is zero as viscous dampers have no force resistance at rest. For the AFS2 system, the threshold $\lambda_{1}$ appears to be between 0.92 and 1.2 , but the actual self-centering

27 threshold can be lower, depending on the viscous-damper contribution (e.g. 53\% of total dissipative force in the prototype model). The conclusion of these analyses is that the existing threshold of

$29 \lambda_{1} \geqslant 1.25$ typically used to account for material over-strength in FS design is still applicable for the AFS systems. 


\section{EQE 983}
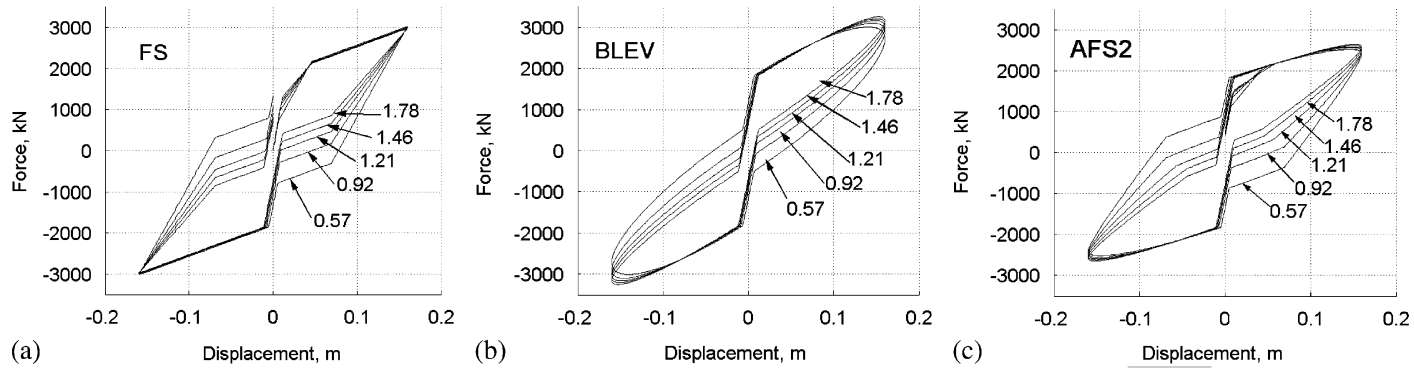

Figure 9. Influence of $\lambda_{1}$ ratio-the force/moment ratio between contribution from self-centering and energy dissipation elements for: (a) FS; (b) BLEV; and (c) AFS2.

The second parameter $\lambda_{2}$ is the ratio between the viscous or velocity-dependent force/moment contributions and the total dissipative force/moment. Equation (4) presents a generic form of $\lambda_{2}$.

3 The $\lambda_{2}$ ratio controls the distribution of velocity-dependent and displacement-dependent dissipation of the system. Therefore, by limiting $\lambda_{2}$ to a threshold value, the system can be designed to avoid excessive force/acceleration with high velocity excitation. The velocity-dependent force/moment contribution, $F_{\mathrm{v}}$ can be also controlled by limiting the threshold friction slip force for the AFS2 system

$$
\lambda_{2}=\frac{M_{\text {velocity-dependent-dissipation }}}{M_{\text {total-dissipation }}} \approx \frac{F_{\mathrm{V}}}{F_{\mathrm{EP}}+F_{\mathrm{V}}}=\frac{F_{\mathrm{V}}}{F_{\mathrm{BLE}}} \lambda_{1}
$$

9 The full range $(0-1)$ of the $\lambda_{2}$ ratio would define all the systems discussed in this paper: BLEV systems have a $\lambda_{2}$ ratio equal to 1 (100\% viscous-damping), whereas traditional FS systems have

11 a $\lambda_{2}$ ratio equal to 0 (no viscous contribution). AFS systems are between these two extremes. For instance, the calibrated SDOF AFS2 model for the prototype bridge pier has a $\lambda_{2}$ ratio of 0.56 , for

13 the given range of velocity assumed. Table II presents a qualitative force-displacement view of the relationship between $\lambda_{1}$ and $\lambda_{2}$ on the hysteretic behaviour of the AFS hysteresis systems. It is

15 evident that as $\lambda_{1}$ increases, the hysteretic energy dissipated by the systems decreases. Conversely, as $\lambda_{2}$ increases, the velocity-dependent damping increases, which can then lead to higher energy

17 dissipation in extreme earthquake events such as those with near-fault directivity effects.

\subsection{Effective damping (equivalent viscous damping)}

The equivalent viscous damping values $\xi_{\text {eq,SYS }}$ of the each system can be evaluated from the hysteresis dissipation contribution at a range of displacement ductility levels for varying levels of excitation velocities (low, moderate and high velocities). Using area-based (geometric stiffness) method [40], the equations for the relationship between $\xi_{\text {eq,SYS }}$ and ductility can be derived analytically for AFS systems:

$$
\begin{aligned}
& \xi_{\text {eq }, \mathrm{AFS}}=\xi_{\text {Elastic }}+\xi_{\text {Viscous }}+\xi_{\text {Hysteretic }} \\
& \xi_{\text {eq, AFS }}=\xi_{\text {Elastic }}+\frac{\lambda_{2}}{2\left(\lambda_{1}+1\right) \mu^{0.25}} \beta_{V} S_{V}\left\{T_{\text {Eff }}\right\}+\frac{\left(1-\lambda_{2}\right)}{\left(\lambda_{1}+1\right)} \frac{2(\mu-1)(1-r)}{\pi \mu(1+r(\mu-1))}
\end{aligned}
$$




\section{EQE 983}

Table II. Qualitative force-displacement of systems with varying values of $\lambda_{1}$ and $\lambda_{2}$.

\begin{tabular}{|c|c|c|c|c|}
\hline \multirow{2}{*}{$\lambda_{1}=\frac{M_{\text {RE-CENTERING }}}{M_{\text {DISSIPATNG }}}$} & \multicolumn{3}{|c|}{$\lambda_{2}=\frac{M_{\text {VIScous }}}{M_{\text {DISSIPATING }}}$} & \\
\hline & $\lambda_{2}=0.0$ & $\lambda_{2}=0.5$ & $\lambda_{2}=1.0$ & \\
\hline$\lambda_{1}=0.0$ & EP & VEP & & $\begin{array}{l}\text { LEGEND: } \\
\text { EP: Non-Linear } \\
\text { Elastoplastic }\end{array}$ \\
\hline$\lambda_{1}=0.5$ & & & & $\begin{array}{l}\text { plastic } \\
\text { V: Viscous (Viscous } \\
\text { dampers assumed) }\end{array}$ \\
\hline$\lambda_{1}=1.0$ & & & & $\begin{array}{l}\text { BLEV: Bi-linear } \\
\text { Elastic \& Viscous }\end{array}$ \\
\hline$\lambda_{1}=1.25$ & $\mathrm{FS}^{\circ}$ & AFS & BLEV & \\
\hline
\end{tabular}

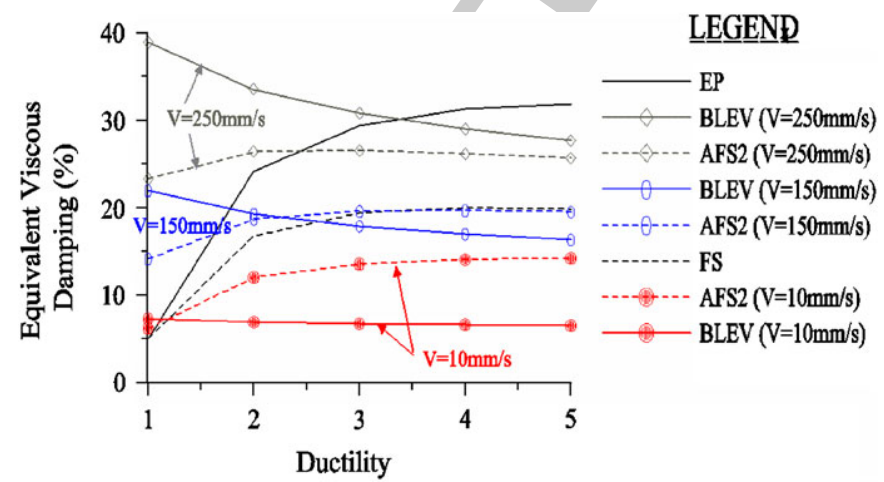

Figure 10. Area-based equivalent viscous damping, $\xi_{\text {eq,SYS }}-$ ductility relationship for the prototype SDOF systems, as described by Equation (6) (AFS system: $\lambda_{1}=1.21$ and $\lambda_{2}=0.54$ ).

1 where $r$ is post-yield stiffness, $\mu$ is the design structural ductility, $\beta_{\mathrm{V}}$ is a damping reduction factor (depending on the dampers' placement, e.g. for SDOF, $\beta_{\mathrm{V}} \approx 1.0$ ) and $S_{\mathrm{V}}\left\{T_{\mathrm{Eff}}\right\}(\mathrm{inm} / \mathrm{s}$ ) is

3 the velocity spectra ordinate corresponding to the effective period, $T_{\text {Eff. }}$ Equation (6) is plotted in Figure 10 for various $\lambda_{1}, \lambda_{2}$ ratios and excitation velocities. The equation and curves are useful

5 in design within a direct-displacement-based design (DDBD) framework [47]. The results for the elastoplastic and flag-shape systems are consistent with the existing design equations derived and

7 given for DDBD [39, 40,47]. The influence of higher excitation velocities is more significant in BLEV system with higher $\lambda_{2}$ ratio, in comparison with AFS system. While not elaborated here, a

9 correction factor is needed to reduce the area-based equivalent viscous damping with calibration to non-linear time-history analyses result [39]. 


\section{NON-LINEAR DYNAMIC TIME-HISTORY ANALYSES}

\subsection{Non-linear time-history analyses}

3 Non-linear time-history analyses (NLTHA) were carried out on the prototype SDOF hysteresis models described in Section 4.1 to verify the enhanced performance of the AFS systems. Analyses

5 were done using the finite-element program RUAUMOKO2D [48] and a Newmark-beta integration scheme with a time-step of $0.002 \mathrm{~s}$. A Rayleigh damping model proportional to the tangent stiffness

7 was used specifying $5 \%$ of the critical damping.

\subsection{Strong ground motion records}

9 Two suites of strong ground motion records were used, representing both far-field and nearfault events. The elastic response spectra for both suites are shown in Figure 11. The first suite

11 of earthquakes is an ensemble of 20 scaled historical 'far-field' strong ground motion records from California and representative of earthquakes having a probability of exceedance of $10 \%$ in

1350 years. These records were related to soil types C or D (NEHRP categories [1]), with hypocentre depth ranging between 13 and $25 \mathrm{~km}$. The characteristics of the far-field suite of records are

15 presented in Table III. The second suite of earthquakes is an ensemble of 20 historical earthquake records, selected based on its PGV/PGA ratio (at least $0.08 \mathrm{~g} / \mathrm{ms}^{-1}$ ) and distance from fault (less

17 than $10 \mathrm{~km}$ ). The near-fault earthquake suite is checked to ensure clear forward directivity and/or fling effect is observed within the ground motion records. The source mechanism and soil type

19 are selected such that a range of different properties are considered. The characteristics of the near-fault suites are presented in Table IV. Scaling of the earthquakes was done according to

21 the standard FEMA [1] approach.

\subsection{Comparison of NLTH seismic response of the four SDOF systems}

23 Figures 12(a)-(d) present the NLTHA responses under both suites of earthquakes for all four SDOF systems. The figures show the scatter plots of all the NLTHA results and the horizontal bar

25 indicates the mean and the mean \pm one standard deviation (STDV) of the result.
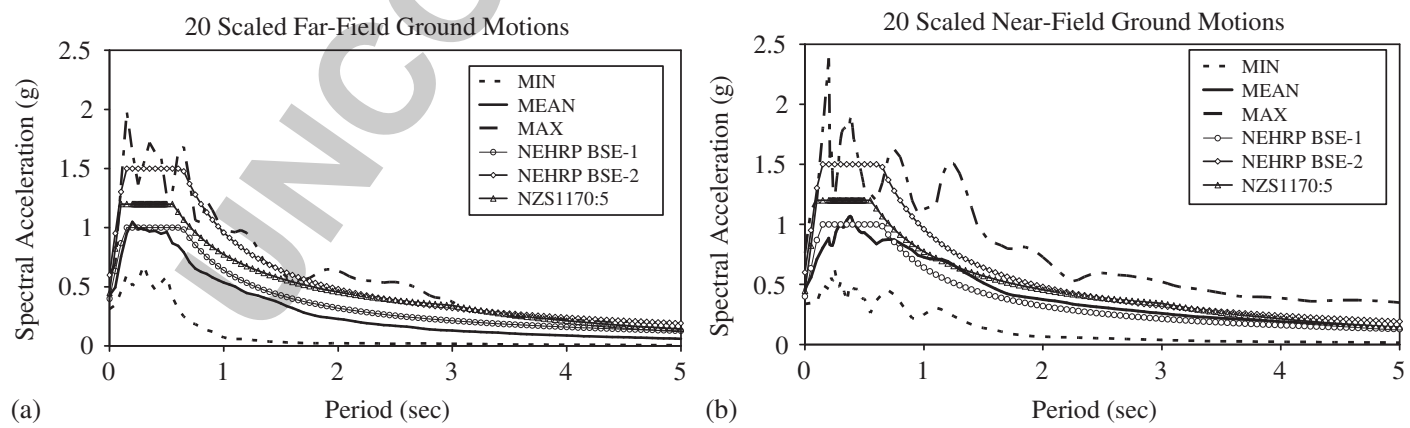

Figure 11. Acceleration response spectra: (a) 20 scaled far-field ground motions and (b) 20 scaled near-fault ground motions. 


\section{EQE 983}

W. Y. KAM $E T A L$.

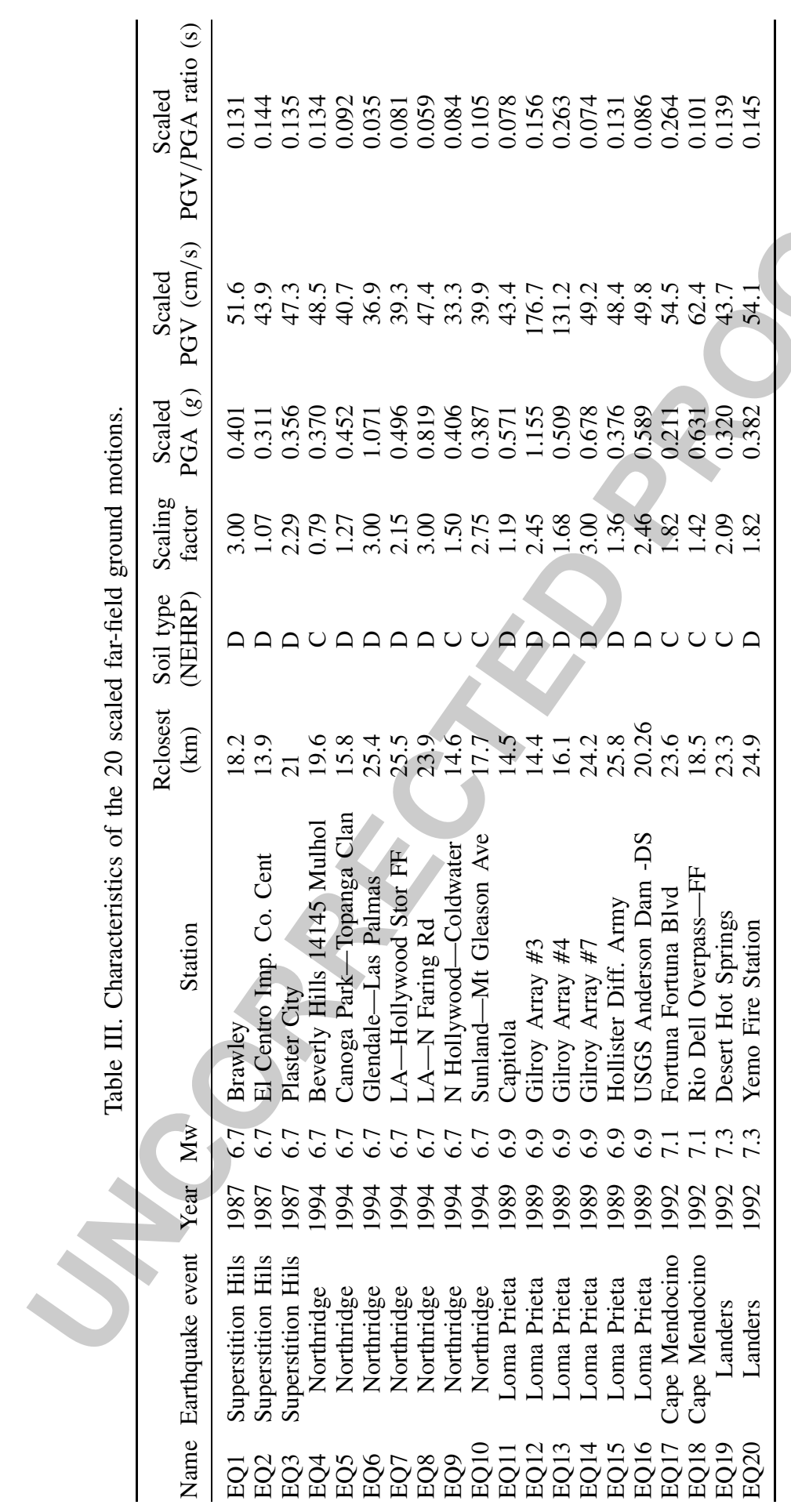

Copyright (C) 2009 John Wiley \& Sons, Ltd.

Earthquake Engng Struct. Dyn. (2009)

DOI: $10.1002 /$ eqe 


\section{EQE 983}

SELF-CENTERING STRUCTURAL SYSTEMS

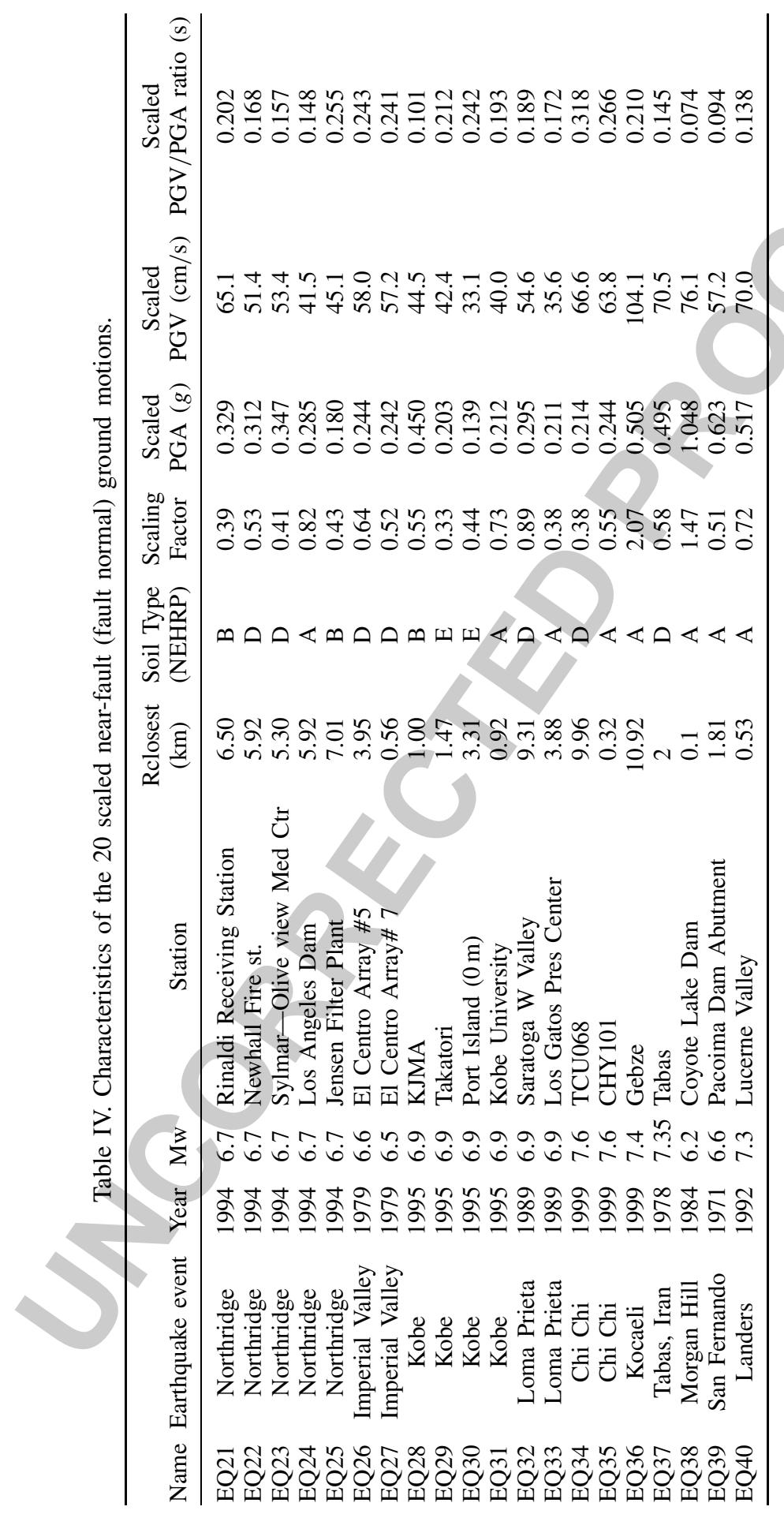




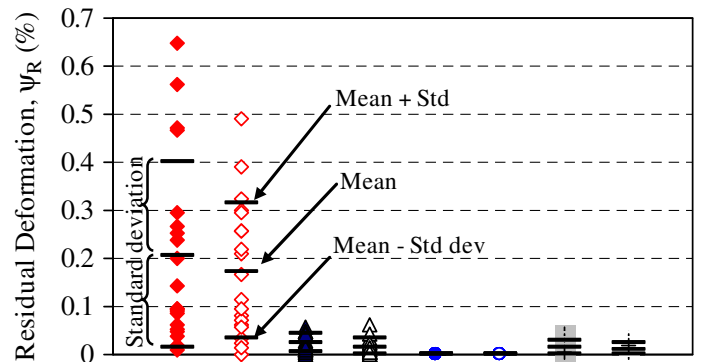

(a)

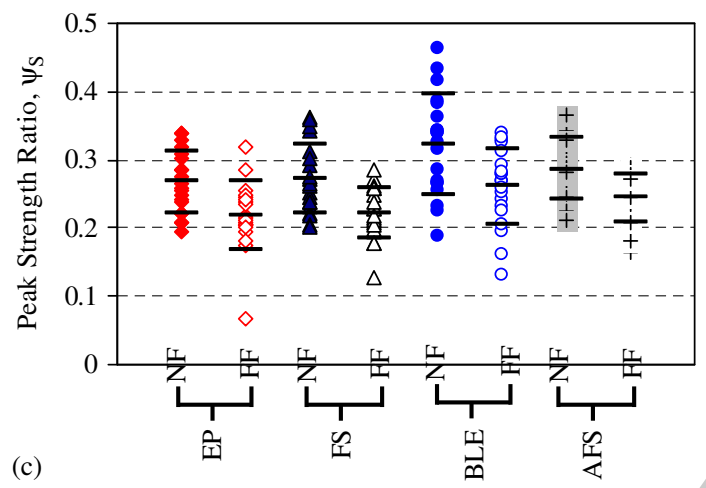

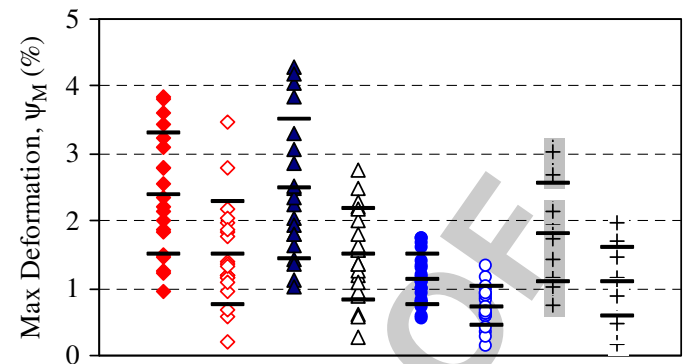

(b)

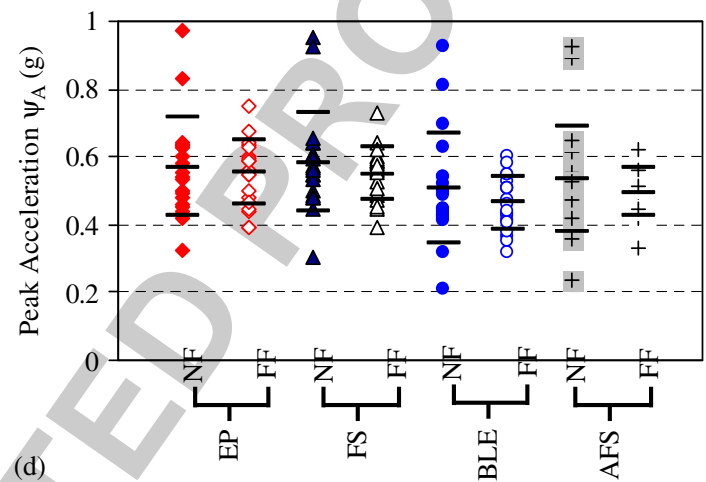

Figure 12. Scatter plot and statistical results of NLTHA on four SDOF systems under: far-field (FF) and near-fault (NF) earthquakes: (a) residual deformation, $\psi_{\mathrm{R}}$; (b) maximum deformation, $\psi_{\mathrm{M}}$; (c) peak strength ratio, $\psi_{\mathrm{S}}$; and (d) peak acceleration, $\psi_{\mathrm{A}}$.

The performance of the different systems in terms of the three performance indices described in Section 2.2 and strength ratio, $\psi_{\mathrm{S}}$, is compared and the following observations can be made:

(1) Residual drift, $\psi_{\mathrm{R}}$ : Based on Figure 12(a), EP systems have significant $\psi_{\mathrm{R}}$, up to $0.65 \%$, indicative of possible loss of functionality in the large seismic event. The high post-yield stiffness in the prototype structure, however, reduces the $\psi_{\mathrm{R}}$ of the EP system.

(2) EP vs self-centering systems: In addition to the higher $\psi_{\mathrm{R}}$, it is interesting to note that the EP system has similar deformation demand $\left(\psi_{\mathrm{M}}\right)$ to the FS system without significant increase in $\psi_{\mathrm{S}}$ consistently with previous studies $[11,26]$.

(3) Hysteretic vs viscous damping only-FS vs BLEV: The systems with viscous dampingonly, BLEV have lower $\psi_{\mathrm{M}}$ and $\psi_{\mathrm{A}}$ responses. Naturally, the trade off for the improved performance is a considerable increase in the $\psi_{\mathrm{S}}$ for BLEV when compared with other systems. In a real structure, this would indicate higher required strengths of the superstructure and foundation. Particularly, in near-fault events, the $\psi_{\mathrm{S}}$ response of BLEV is $24 \%$ higher on an average with a larger scatter than in the far-field events, as the viscous dampers are very much sensitive to the scatter of the excitation velocities. $\psi_{M}$ for BLEV is about half of the $\psi_{\mathrm{M}}$ for FS, highlighting the improved energy dissipation from viscous dampers.

(4) Advanced self-centering with viscous dampers-BLEV vs AFS2: With velocity-dependent energy dissipation, both BLEV and AFS2 systems have lower mean $\psi_{\mathrm{M}}$, responses with 
lower dispersion (low STDV values) in both far-field and near-fault cases. It can be seen here that the $\psi_{\mathrm{M}}$ of BLEV is much lower than the design drift (2\%), indicating significant conservatism in the calibration velocity of $150 \mathrm{~mm} / \mathrm{s}$. For the design of the BLEV and AFS2 systems with significant velocity-dependent energy dissipation, it is proposed to vary the design velocity based on the design velocity spectra and effective period [49].

(5) Strength ratio, $\psi_{\mathrm{S}}-B L E V$ vs EP, FS and AFS2: One common criticism on adding supplementary viscous damping is the possible increase in base-shear either from stiffening of the structure, particularly when introducing bracing systems, or excessive viscous damping forces from high-velocity events. As mentioned in (3), the BLEV systems have significantly higher $\psi_{\mathrm{S}}$ particularly in near-fault events when compared with conventional EP and FS systems. In contrary, the AFS2 system managed to control the $\psi_{\mathrm{S}}$ ratio with the added friction-slip element, thus limiting the force within the viscous dampers.

(6) Peak acceleration, $\psi_{\mathrm{A}}$ : Figure $12(\mathrm{~d})$ shows that average $\psi_{\mathrm{A}}$ is relatively constant across all systems, with increasing $\psi_{\mathrm{S}}$ (and hence dissipated energy) decreases corresponding acceleration demand, $\psi_{\mathrm{A}}$ (corresponding inertia force). It is worth noting that $\psi_{\mathrm{A}}$ would be a more critical parameter in multi-degree-of-freedoms (MDOF) structures. Preliminary analysis on MDOF structures of the same four SDOF systems has shown a $26 \%$ reduction in the floor accelerations for AFS2 [49].

(7) Overall performance: AFS2 system provides more consistent performance in terms of all performance indicators, $\psi_{\mathrm{M}}, \psi_{\mathrm{R}}$ and $\psi_{\mathrm{S}}$

\section{5.4. Seismic response under far-field earthquakes}

To further illustrate the seismic response of the different systems, a time-history response of the

23 SDOF systems for one far-field event (Capitola Station, Loma Prieta 1989 earthquake) is shown in Figure 13. All self-centering systems achieved zero residual displacement, $\psi_{\mathrm{R}}$, with clear flagshaped hysteresis response. All the systems achieved satisfactory $\psi_{\mathrm{S}}$ and $\psi_{\mathrm{M}}$ responses-indicative of satisfactory assumption of the $\xi_{\text {sys }}$ under far-field earthquakes. The performance of self-centering

27 systems was not compromised by the lower $\xi_{\text {sys }}$ (given in Table I), consistent with previous research $[11,12,26]$. The energy dissipation in the BLEV system is less effective at the lower excitation

29 velocity of far-field earthquakes - particularly when compared with the AFS2 system.

\subsection{Seismic response under in near-fault earthquakes and near-fault effects}

31 A time-history response of the alternative SDOF systems for one near-fault event (Gebze Station, Kocaeli 1999 earthquake) is shown in Figure 14 The EP system exhibited significant 'crawling'

33 towards the negative displacement with relatively high $\psi_{\mathrm{R}}$. FS system performed satisfactorily when compared with EP, but with zero $\psi_{\mathrm{R}}$. Self-centering systems with viscous energy dissipation

35 (BLEV and AFS) performed significantly better, with lower $\psi_{\mathrm{M}}$ and zero $\psi_{\mathrm{R}}$. In contrary to the far-field earthquake response of the BLEV system, higher $\psi_{\mathrm{S}}$ from the unconstrained BLEV

37 system is observed in this near-fault event. And evidently, the AFS2 system, where the friction-slip element in AFS2 connection limits the peak viscous damping force, has a lower $\psi_{\mathrm{S}}$. Generally,

39 all systems performed better in far-field excitations compared with near-fault excitations, with 55-69\% amplification in the $\psi_{\mathrm{M}}$ (Figure 12(b)). In comparison with the far-field earthquake

41 example, systems with hysteretic-only energy dissipation have higher $\psi_{\mathrm{M}}$ under near-fault excitation as expected. The efficiency and advantage of AFS systems (BLEV and AFS2) are more appreciable 43 in near-fault earthquakes. 


\section{EQE 983}
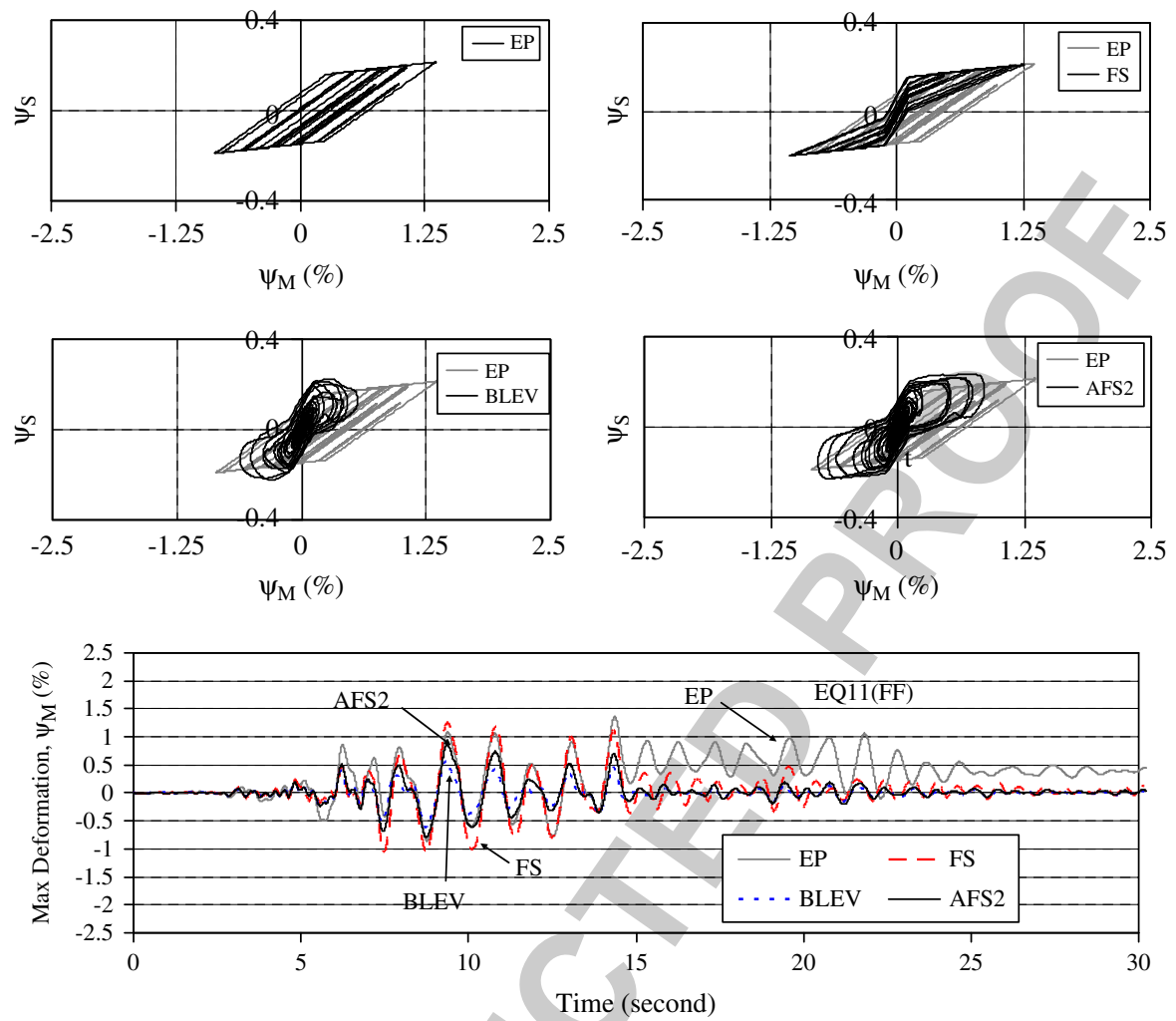

Figure 13. Example of non-linear time-history and force-displacement responses of four SDOF systems under far-field earthquake (Capitola Station, Loma Prieta, CA 1989 earthquake).

\section{5.6. Limitation of the SDOF analysis}

Non-linear analysis of the SDOF system can simplify the complexity of the non-linear response of structures under earthquake loading. In addition to modelling near-SDOF structures, SDOF analysis is also a close approximation to the real-structure behaviour using the substitute-structure approach [47]. The use of inelastic SDOF analysis also allows the generation of inelastic design spectra that can be used for design. While the SDOF analysis performed in this study shows

7 the general trend of the seismic response and the associated governing global parameters of the different systems, it has some acknowledged limitations, particular when extending to real MDOF structures.

Typically, hysteretic damping can be easily added in parallel to the self-centering elements

11 [2-5,7-10]. Considering the complexity of adding supplementary viscous dampers to actual structures, where the geometric positioning and kinematic consideration of the devices are crucial to

13 the performance of these devices, the proposed SDOF systems may be less realistic when extending from a bridge pier or wall system to a MDOF building. In addition, the rate of deformation

15 (velocity) induced on the viscous dampers can be influenced by its placement on the structure and the geometry of the MDOF structure. 

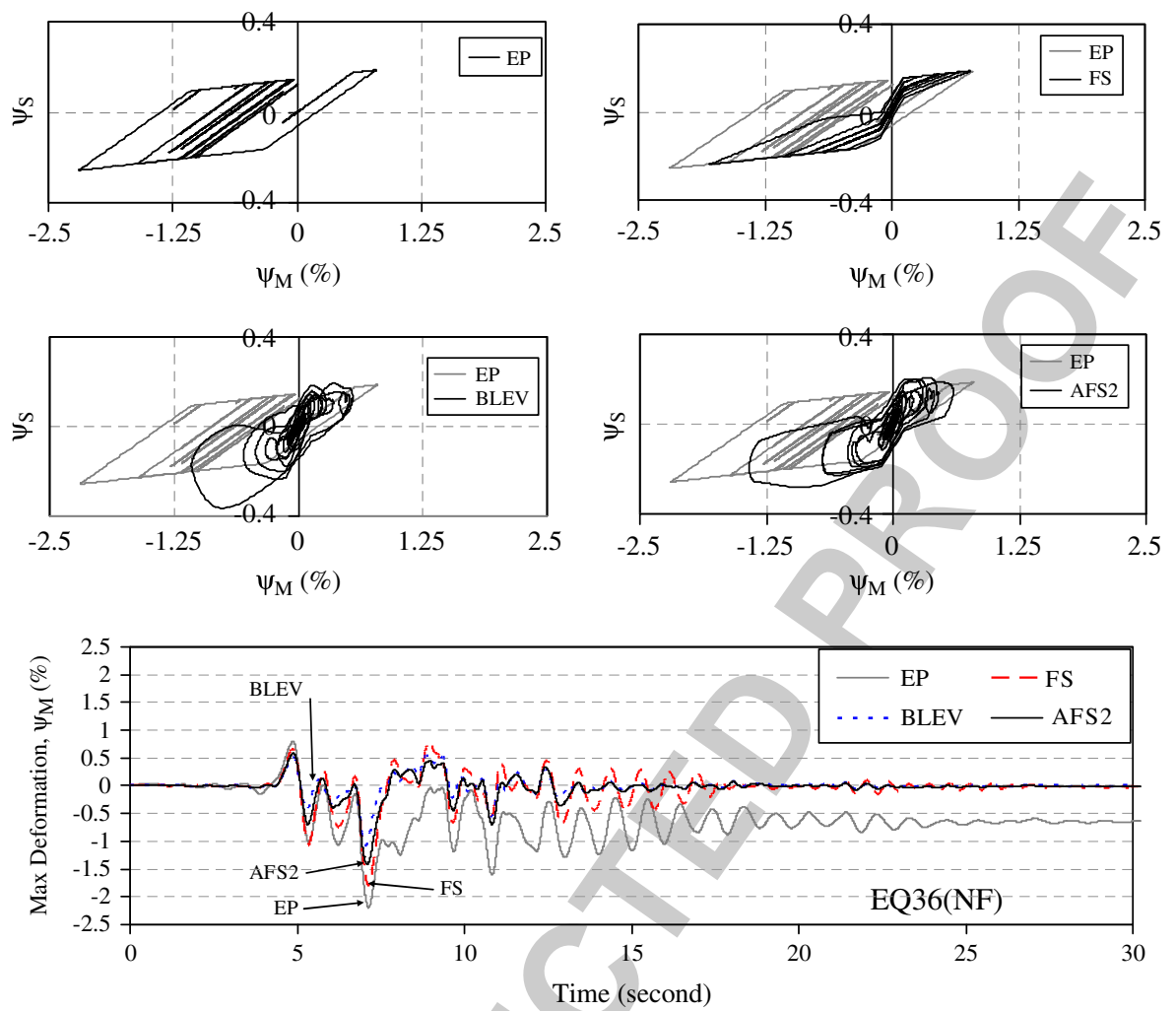

Figure 14. Example of non-linear time-history and force-displacement responses of four SDOF systems under near-fault earthquake (Gebze Station, Kocaeli, Turkey 1999 earthquake).

1 Several studies have considered further the practical placement and its implication on the seismic response of the self-centering systems. Kurama [41] proposed the placement of viscous dampers as diagonal braces connected to rocking walls. Marriott [43] has investigated the kinematic effect of dampers connected at the base of a rocking wall in which the achieved global damping (in terms of equivalent viscous damping) is in the order of 5-20\% of the provided viscous damping [43]. In considering the reduction in induced velocity up the structure, Kam et al. [49] have

7 proposed equations to approximate effective velocity of viscous dampers for AFS MDOF frame structures.

\section{PARAMETRIC ANALYSIS OF ADVANCED FLAG SHAPE 2 (AFS2) SYSTEMS}

\subsection{Range of key parameters for AFS2 systems}

11 The parametric study is carried out over a range of initial period of 0.2-3.0 s using the suites of earthquakes presented in Section 5.2. Three parameters are considered: the moment ratio $\lambda_{1}$, the

13 viscous-hysteretic dissipation ratio $\lambda_{2}$ and the yield strength ratio $\psi_{S-Y}$. Three realistic values of 


\section{EQE 983}



Figure 15. Inelastic spectra for average maximum drift, $\psi_{M}$ for AFS hysteretic systems under far-field earthquakes ( $Y$-axis: $\psi_{\mathrm{M}}(\%) ; X$-axis: period $T$ (s).

1 the strength ratio $\psi_{S-Y}$ are considered: $0.05 W_{\text {SDOF }} 0.15 W_{\text {SDOF }}$ and $0.5 W_{\text {SDOF }}$ representing weak, moderately strong and very strong systems. $\lambda_{1}$ is taken to range from 0.8 to 1.6 , giving a higher and

3 lower range of self-centering capacity for the systems. Lastly, $\lambda_{2}$ is taken to range from 0 to 1.0 , to fully describe the full spectrum of self-centering systems without any velocity-dependent energy

5 dissipation (i.e. $\mathrm{FS}-\lambda_{2}=0$ ) up to systems with $100 \%$ velocity-dependent energy dissipation (i.e. BLEV $-\lambda_{2}=1$ ). Constant and realistic values of post-yield stiffness of 0.075 and SDOF weight,

$7 \quad W_{\text {SDOF }}$ of $12,000 \mathrm{kN}$ are used.

\subsection{Parametric analysis result-maximum deformation parameters, $\psi_{\mathrm{M}}$}

9 The mean values over the suites of far-field and near-fault earthquakes of the $\psi_{\mathrm{M}}$ are given in Figures 15 and 16, respectively. 


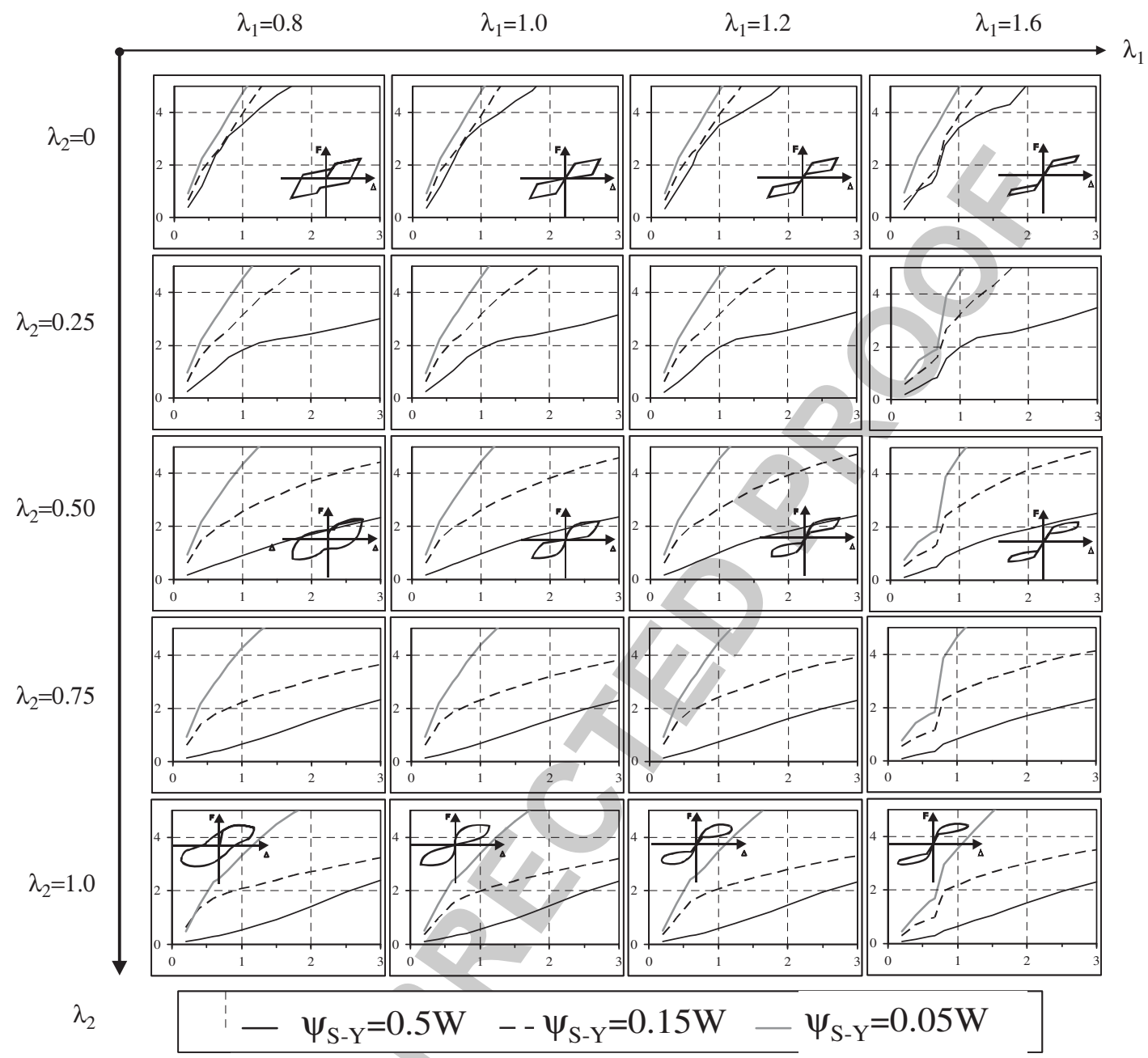

Figure 16. Inelastic spectra for average maximum drift, $\psi_{\mathrm{M}}$ for AFS hysteretic systems under near-fault earthquakes ( $Y$-axis: $\psi_{\mathrm{M}}(\%) ; X$-axis: period $T$ (s).

1 6.2.1. Influence of $\lambda_{1}$ ratio. Primarily, the $\lambda_{1}$ ratio is to control the level of residual deformation, $\psi_{\mathrm{R}}$, hence the self-centering capacity. From the result shown in Figures 15 and 16, it is observed

3 that $\lambda_{1}$ ratio has no significant effect on $\psi_{\mathrm{M}}$ in both the far-field set and near-fault set of earthquakes. This implies that while increasing $\lambda_{1}$ ratio decreases the energy dissipation capacity in terms

5 of $\xi_{\text {eq }}$, the decrease of $\xi_{\text {eq }}$ is not too significant, particularly for the typical design range of $\lambda_{1}$ ratios $(0.8-1.6)$. This is consistent with previous research [11] on self-centering FS systems with

7 varying $\lambda_{1}$ ratio (expressed as $\left.\beta=1 / \lambda_{1}\right)$. This is also implied in Figure 10 for FS system $\left(\lambda_{2}=0\right)$, $\xi_{\mathrm{SYS}}$ is rather consistent for medium-high ductility values, $\mu>2.0$. The influence of $\lambda_{1}$ on the

$9 \quad \psi_{\mathrm{M}}$ responses increases as the system becomes stronger (when $\psi_{S-Y}$ is $\geqslant 0.15 W_{\mathrm{SDOF}}$ ) and as the level of viscous damping increases (when $\lambda_{2}$ is $\geqslant 0.5$ ). Thus, by satisfying $0.8<\lambda_{1}<1.6$, sufficient

11 energy dissipation is provided, particularly for the AFS system with some viscous damping. 


\section{EQE 983}

1 6.2.2. Influence of $\lambda_{2}$ ratio. It can be seen that with minor addition of viscous energy dissipation (e.g. $\lambda_{2} \geqslant 0.25$ ), significant reduction in the maximum drift demand, $\psi_{\mathrm{M}}$ (up to $50 \%$ ) can be

3 achieved. With increasing $\lambda_{2}$ ratios, $\psi_{\mathrm{M}}$ generally decreases. This reduction of $\psi_{\mathrm{M}}$ with increasing $\lambda_{2}$ is more significant for moderately strong and weak systems $\left(\psi_{S-Y} \leqslant 0.15 W_{\mathrm{SDOF}}\right)$. However,

5 for weak systems $\left(\psi_{S-Y}=0.5 W_{\mathrm{SDOF}}\right)$ in near-fault earthquakes, it was found that $\lambda_{2}$ has lower efficiency in reducing $\psi_{\mathrm{M}}$, as the fling-pulse effect would effectively push the seismic response

7 to the post-yield stiffness branch for most of the weak systems. For very strong systems $\left(\psi_{S-Y}=\right.$ $0.5 W_{\mathrm{SDOF}}$ ), the response is dominated by the non-linear elastic spring (un-bonded post-tensioned

9 tendons), such that the systems are behaving linearly ( $\xi_{\text {eq }} \approx \xi_{\text {Elastic }}$ ), thus are not sensitive to $\lambda_{1}$ and $\lambda_{2}$ ratios. Therefore, to control $\psi_{\mathrm{M}}$ response of AFS systems, $\lambda_{2}$ is suggested to be at least 0.25 .

11 6.2.3. Near-fault earthquakes effect and design implications. Comparing the inelastic spectra generated by the near-fault earthquakes (Figure 16) to the inelastic spectra generated by the far-

13 field earthquakes (Figure 15), a significant amplification of $\psi_{M}$ response (up to 100-200\%) can be clearly observed, particularly for SDOF systems with period exceeding $1.0 \mathrm{~s}$ and SDOF systems

15 without velocity-dependent energy dissipation $\left(\lambda_{1}=0\right)$. This highlights the necessity to explicitly consider the near-fault source effects in the design. With increasing $\lambda_{2}$ ratios, the $\psi_{\mathrm{M}}$ decreases

17 significantly, as higher excitation velocity in near-fault earthquakes induced higher energy dissipation from the viscous dampers. It is also observed that the influence of $\lambda_{1}$ on the seismic response

19 is more significant in near-fault excitation, as the amount of energy dissipation is more critical.

For far-field earthquakes, the $\psi_{S-Y}$ of the SDOF systems has less influence on the $\psi_{\mathrm{M}}$, partic-

21 ularly for systems with low $\lambda_{2}$ ratio. However, in near-fault excitations, the $\psi_{S-Y}$ of the system can affect the $\psi_{\mathrm{M}}$ significantly. In controlling the $\psi_{\mathrm{M}}$ in near-fault earthquakes, the advantage of

23 having viscous energy dissipation (as per AFS systems) becomes more obvious. With increasing $\lambda_{2}$ ratio, the $\psi_{\mathrm{M}}$ decreases measurably, as higher excitation velocity in near-fault earthquakes induced

25 higher energy dissipation from the viscous dampers. For example, to achieve $\psi_{\mathrm{M}}=2.0 \%$ (typical drift limit states corresponding to Ultimate Limit State design $[1,22]$ ), with low $\lambda_{2}$ ratio, the system 27 has to be stiff and strong (e.g. $T_{\mathrm{SDOF}} \leqslant 0.4 \mathrm{~s}, \lambda_{2}=0$ and $\psi_{S-Y}=0.15 W_{\mathrm{SDOF}}$ ). With increasing $\lambda_{2}$ ratio, the required stiffness decreases (e.g. $T_{\mathrm{SDOF}} \leqslant 1.0 \mathrm{~s}, \lambda_{2}=1.0$ and $\left.\psi_{S-Y}=0.15 W_{\mathrm{SDOF}}\right)$. Thus,

29 the inelastic spectra given in Figure 16 can be a useful design chart for AFS systems.

\subsection{Residual drift, $\psi_{\mathrm{R}}$}

31 The $\psi_{\mathrm{R}}$ responses of AFS2 systems for both far-field and near-fault earthquakes for the range of $\lambda_{1}$ and $\lambda_{2}$ ratios considered are insignificant, thus not shown here. The $\psi_{\mathrm{R}}$ is less $0.10 \%$ for 33 most cases except for systems with $\lambda_{1}=0.8$ and $\lambda_{2}=0$. With increasing $\lambda_{1}$ and $\lambda_{2}, \psi_{\mathrm{R}}$ exhibits a decreasing trend. The design yield strength of the SDOF systems, $\psi_{S-Y}$ seems to have negligible

35 effect on $\psi_{\mathrm{R}}$. In general, for $T_{\mathrm{SDOF}}>0.2 \mathrm{~s}$, the adoption of $\lambda_{1}>0.8$ would ensure self-centering capacity for most AFS systems (with any $\lambda_{2}$ and $\psi_{S-Y}$ ).

\section{6.4. Parametric analysis result-maximum acceleration, $\psi_{\mathrm{A}}$}

The mean values over the suite of near-fault earthquakes of the normalized maximum acceleration

39 damage index, $\psi_{\mathrm{A}}$, is given in Figure 17. In general, $\psi_{\mathrm{A}}$ ratio decreases with decreasing values of strength ratio, $\psi_{S-Y}$ and with increasing period. However, for AFS systems $\left(\lambda_{2} \geqslant 0.25\right)$ with very

41 short period $(T \leqslant 0.4 \mathrm{~s})$, the $\psi_{\mathrm{A}}$ is higher for weak systems and lower for stronger systems. For these very stiff, yet weak AFS systems, the $\psi_{\mathrm{A}}$ response is amplified by the very high displacement 


\section{EQE 983}

SELF-CENTERING STRUCTURAL SYSTEMS

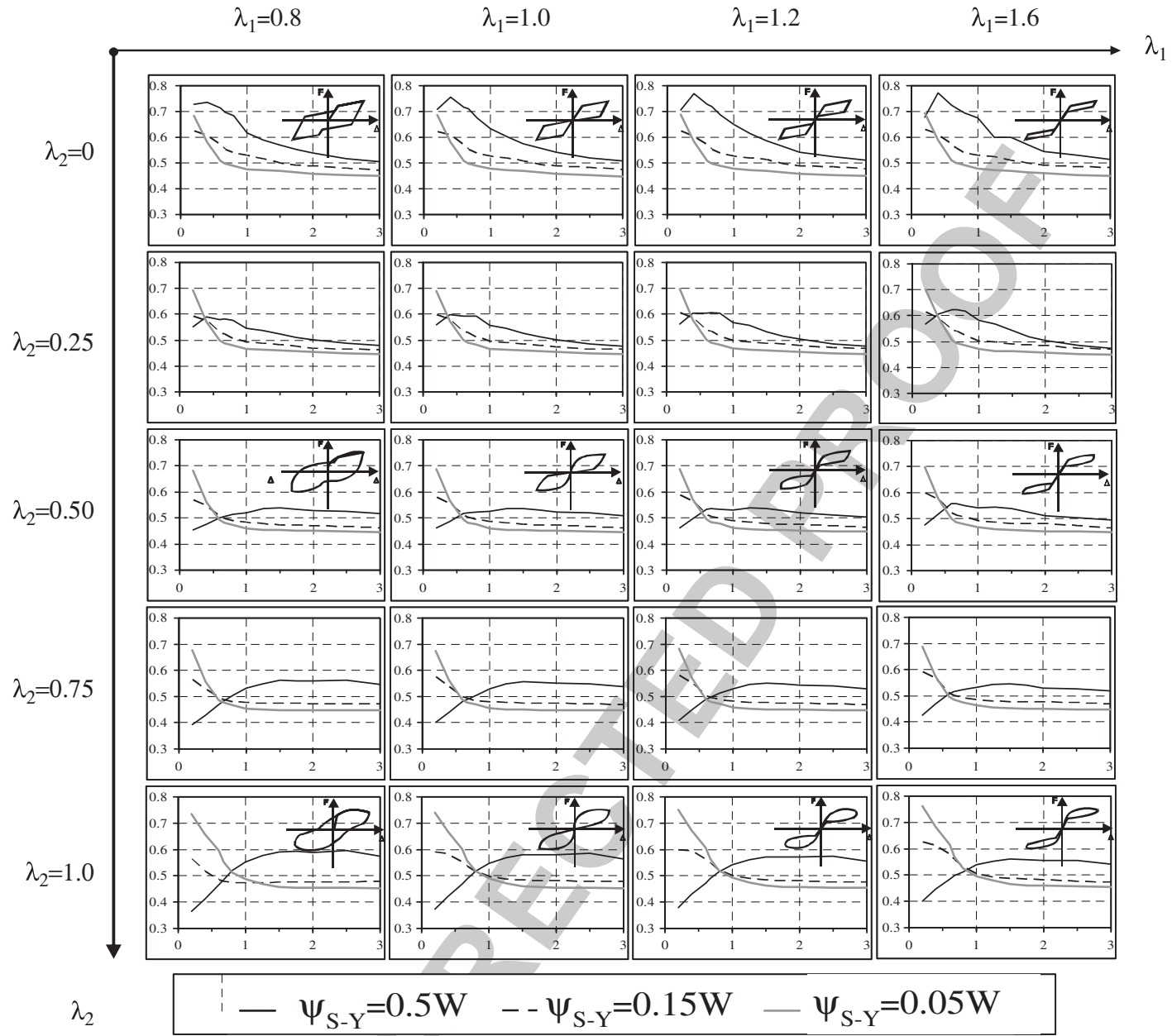

Figure 17. Inelastic spectra for average maximum acceleration, $\psi_{\mathrm{A}}$ for AFS hysteretic systems under near-fault earthquakes. $\left(Y\right.$-axis: $\psi_{\mathrm{A}}(\mathrm{g}) ; X$-axis: period (s).

1 ductility and large post-yield stiffness, $r(0.075 \times$ initial stiffness $)$. As $\lambda_{2}$ increases, there is a trend of reduction in $\psi_{\mathrm{A}}$. This is associated with the increased energy dissipation, particularly derived

3 from velocity-dependent dampers highly activated in the near-fault events. However, for SDOF structures, $\psi_{\mathrm{A}}$ does not vary significantly due to the lack of MDOF amplification.

\section{CONCLUSIONS}

This paper introduced and demonstrated the use of combination of various alternative energy

7 dissipation elements (hysteretic, viscous or visco-elasto-plastic) in series and/or in parallel to selfcentering elements for self-centering systems. The velocity-proportional viscous and displacement 


\section{EQE 983}

1 proportional hysteretic energy dissipations in the so-called Advanced Flag-Shape (AFS) systems have improved performance in both near-fault and far-field earthquakes, while still achieving self-

3 centering capability. From NLTHA, AFS systems have lower average maximum and residual drifts with smaller dispersions and without significant increase in base-shear. The analysis result of these

5 self-centering systems also shows that albeit having smaller $\xi_{\text {eq }}$ values, they can achieve higher if not comparable seismic performance, in contrary to the 'desirable fat hysteresis loop' assumption.

7 High damping forces from velocity-dependent dampers can be controlled by implementing a friction slipping element in series with a viscous damping contribution as in the AFS.

9 The inelastic displacement and acceleration spectra generated from the extensive parametric analysis on SDOF AFS systems on both suites of far-field and near-fault earthquakes have shown the

11 influences of two design parameters, $\lambda_{1}$ and $\lambda_{2}$ (representing, respectively, the ratio of self-centering vs energy dissipation moment contribution and the ratio of viscous vs hysteretic dissipating contri-

13 bution) on the seismic behaviour of the AFS systems. For the design of self-centering systems with combined hysteretic and viscous energy dissipation (AFS) systems, the ratio $\lambda_{1}$ is recommended to

15 be at least $0.8-1.6$ while the ratio $\lambda_{2}$ is $0.25-0.75$ to ensure sufficient self-centering and energy dissipation capacities, respectively.

17 While the AFS systems have shown tremendous potential structurally, more refined analytical and experimentally investigations on MDOF structures and dynamic shaking-table tests are ongoing 19 at the University of Canterbury, to confirm the viability of this second generation of self-centering systems. More necessarily, industry cooperation in developing economical velocity-dependent 21 dampers is crucial in furthering this system.

\section{ACKNOWLEDGEMENTS}

The financial support provided by the New Zealand Foundation of Research, Science and Technology under the jointed research project 'Retrofit Solutions for NZ' (FRST Contract No. UOAX0411) is greatly appreciated.

\section{REFERENCES}

1. FEMA-450, NEHRP Recommended Provisions and Commentary for Seismic Regulations for new Buildings and Other Structures. (2003 edition). Federal Emergency Management Agency: Washington DC, 2004.

2. Cheok GS, Lew HS. Performance of precast concrete beam-to-column connections subject to cyclic loading. PCI Journal 1991; 36(3):56-67.

3. Stanton J, Stone WC, Cheok GS. A hybrid reinforced precast frame for seismic regions. PCI Journal 1997; 42(2):20-32.

4. Priestley MJN, Sritharan S, Conley JR, Pampanin S. Preliminary results and conclusions from the PRESSS five-story precast concrete test building. PCI Journal 1999; 44(5):42-67.

5. Mander JB, Cheng C-T. Seismic resistance of bridge piers based on damage avoidance design. Report No.: Technical Report NCEER-97-0014. SUNY, Buffalo, New York: 1997.

6. Palermo A, Pampanin S, Calvi GM. Concept and development of hybrid solutions for seismic-resistant bridge systems. Journal of Earthquake Engineering 2005; 9(4):1-23.

7. Ricles JM, Sause R, Garlock MM, Zhao C. Postensioned seismic-resistant connections for steel frames. ASCE Journal of Structural Engineering 2001; 127(2):113-121.

8. Christopoulos C, Filiatrault A, Uang C-M. Post-tensioned energy dissipating connections for moment resisting steel frames. ASCE Journal of Structural Engineering 2002; 128(9):1111-1120.

9. Ricles JM, Sause R, Peng SW, Lu LW. Experimental evaluation of earthquake resistant posttensioned steel connections. ASCE Journal of Structural Engineering 2002; 128(7):850-859.

10. Palermo A, Pampanin S, Buchanan A, Newcombe M. Seismic design of multi-storey uildings using Laminated Veneer Lumber (LVL). Proceedings of NZSEE 2005 Conference, Wairakei, NZ, Paper No.14, 2005. 
1 11. Christopoulos C, Filiatrault A, Folz B. Seismic response of self-centering hysteresis SDOF systems. Earthquake Engineering and Structural Dynamics 2002; 31:1131-1150.

3 12. Pampanin S, Christopoulos C, Priestley MJN. Residual Deformations in the Performance-Based Seismic Assessment of Frame Structures. IUSS PRESS: Pavia, Italy, 2002.

5 13. Christopoulos C, Pampanin S, Priestley MJN. Performance-based seismic response of frame structures incl. residual deformations. Part I: Single-degree of freedom systems. Journal of Earthquake Engineering 2003; 7(1):97-118.

14. ACI Innovation Task Group 1. Special Hybrid Moment Frames Composed of Discretely Jointed Precast and Post-Tensioned Concrete Members (ACI T1.2-03) and Commentary (ACI T1.2R-03). American Concrete Institute (ACI). Farmington Hills, MI, 2003.

11 15. fib, Seismic design of precast concrete building structures, fib Bulletin no. 27. International Federation for Structural Concrete (fib). Lausanne, Switzerland, 2003.

13 16. NZS3101, Appendix B: special provisions for the seismic design of ductile jointed precast concrete structural systems. NZS3101: 2006, Concrete Standards. New Zealand Standards; Wellington, NZ, 2006.

15 17. Somerville P, Smith NF, Graves RW, Abrahamson NA. Modification of empirical strong ground motion attenuation relations to include the amplitude and duration effects of rupture directivity. Seismological Research Letters 1997; 68(1):199-222.

18. Bolt BA, Abrahamson NA. Estimation of strong seismic ground motions. International Handbook of Earthquake and Engineering Seismology, IASPEI, Vol II. Academic Press, Elsevier: New York, 2003.

19. Somerville P. Magnitude scaling of the near-fault rupture directivity pulse. Physics of the Earth and Planetary Interiors 2003; 137(1):201-212.

20. Alavi B, Krawinkler H. Behavior of moment-resisting frame structures subjected to near-fault ground motions. Earthquake Engineering and Structural Dynamics 2004; 33(6):687-706.

21. Kalkan E, Kunnath SK. Effects of fling step and forward directivity on seismic response of buildings. Earthquake Spectra 2006; 22(2):367-390.

22. International Conference of Building Officials (ICBO). Uniform Building Code, vol 2. ICBO: Whittier, CA, U.S.A., 1997.

23. Kam WY, Pampanin S, Palermo A, Carr A. Advanced Flag-Shaped systems for high seismic performance. Proceedings of 1ECEES, Geneva, Switzerland, 2006. Paper No. 991.

24. Kwan W-P, Billington SL. Influence of hysteretic behaviour on equivalent period and damping of structural systems. ASCE Journal of Structural Engineering 2003; 129(5):576-85.

25. Farrow K, T, Kurama YC. SDOF Demand index relationship for performance-based seismic design. Earthquake Spectra 2003; 19(4):799-838.

26. Seo CY, Sause R. Ductility demands on self-centering systems under earthquake loading. ACI Structural Journal 2005; 102(2):275-285.

27. Kam WY, Pampanin S, Palermo A, Carr A. Advanced Flag-Shape systems for design and retrofit for near-fault structures. Proceedings of NZSEE 2007 Conference, Palmerston North, 2007.

28. Garlock MM, Sause R, Ricles JM. Behavior and design of posttensioned steel frame systems. ASCE Journal of Structural Engineering 2007; 133(3):389-399.

29. Iyama J, Seo CY, Ricles JM, Sause R. Self-centering steel frame systems with a bottom flange friction device. Journal of Constructional Steel Research 2009; 65(2):314-325.

30. Tremblay R, Lacerte M, Christopoulos C. Seismic response of multi-storey buildings with self centering energy dissipative steel braces. ASCE Journal of Structural Engineering 2008; 134(1):108-120.

31. Christopoulos C, Tremblay R, Kim H-J, Lacerte M. Self-centering energy dissipative bracing system for the seismic resistance of structures: development and validation. ASCE Journal of Structural Engineering 2008; 134(1):96-107.

32. Tremblay R, Christopoulos C, inventors; World International Property Organization (WIPO), assignee Selfcentering energy dissipative brace apparatus with tensioning elements. Worldwide Patent International Publication Number WO/2005/085543. 2005 Submitted. 03 March 2005.

33. Dolce M, Cardone D, Marnetto R. Implementation and testing of passive control devices based on shape memory alloys. Earthquake Engineering and Structural Dynamics 2000; 29(7):945-68.

34. Dolce M, Cardone D, Marnetto R. SMA re-centering devices for seismic isolation of civil structures. Proceedings of Congress of Smart Systems for Bridges, Structures and Highways, SPIE: Bellingham, WA, Newport Beach, 5-7 March 2001; 238-249.

35. Priestley MJN, Tao JR. Seismic response of precast prestressed concrete frames with partially bonded tendons. PCI Journal 1993; 8(1):58-69. 


\section{EQE 983}

1 36. Palermo A, Pampanin S, Buchanan A. Experimental investigations on LVL seismic resistance wall and frame subassemblies. Proceedings of the 1st ECEES; 2006, Geneva, Switzerland, Paper No. 983.

3 37. Morgen BG, Kurama YC. A friction damper for post-tensioned precast concrete moment frames. PCI Journal 2004; 49(3):112-133.

5 38. Rojas P, Ricles JM, Sause R. Seismic performance of posttensioned steel moment resisting frames with friction devices. ASCE Journal of Structural Engineering 2005; 131(3):529-540.

7 39. Blandon CA, Priestley MJN. Equivalent viscous damping equations for direct displacement Based design. Journal of Earthquake Engineering 2005; 9(Special Issue 2):257-278.

9 40. Grant DN, Blandon CA, Priestley MJN. Modelling Inelastic Response in Direct Displacement-based Design. IUSS Press: Pavia, Italy, 2005.

11 41. Kurama YC. Seismic design of unbonded post-tensioned precast concrete walls with supplementary viscous damping. ACI Structural Journal 2000; 97(3):648-658.

13 42. Kurama YC. Simplified seismic design approach for friction-damped unbonded post-tensioned precast concrete walls. ACI Structural Journal 2001; 98(4):705-716.

15 43. Marriott D. The development of high-performance post-tensioned rocking systems for the seismic design of structures. Ph.D. Dissertation. University of Canterbury, Christchurch, 2009.

17 44. Wolski M, Ricles JM, Sause R. Experimental study of a self-centering beam-column connection with bottom flange friction device. ASCE Journal of Structural Engineering 2009; 135(4):479-488.

19 45. Makris N, Chang S-P. Effect of viscous, viscoplastic and friction damping on the response of seismic isolated structures. Earthquake Engineering and Structural Dynamics 2000; 29:85-107.

21 46. Dolce M, Cardone D, Ponzo FC. Shaking-table tests on reinforced concrete frames with different isolation systems. Earthquake Engineering and Structural Dynamics 2007; 36(4):573-596.

23 47. Priestley MJN, Calvi GM, Kowalsky MJ. Displacement-Based Seismic Design of Structures. IUSS Press: Pavia, Italy, 2007.

25 48. Carr A. RUAUMOKO2D-The Maori God of Volcanoes and Earthquakes. University of Canterbury. Christchurch New Zealand 2008. Inelastic Analysis Finite Element program.

27 49. Kam WY, Pampanin S, Palermo A, Carr A. Design procedure and behaviour of Advanced Flag-Shape (AFS) MDOF systems. Proceedings of NZSEE 2008 Conference; Wairakei, NZ, 2008. Paper No.38, 2008. 